NBER WORKING PAPER SERIES

\title{
ELECTRICITY AND FIRM PRODUCTIVITY: \\ A GENERAL-EQUILIBRIUM APPROACH
}

\author{
Stephie Fried \\ David Lagakos \\ Working Paper 27081 \\ http://www.nber.org/papers/w27081 \\ NATIONAL BUREAU OF ECONOMIC RESEARCH \\ 1050 Massachusetts Avenue \\ Cambridge, MA 02138 \\ May 2020
}

For helpful comments we thank Judd Boomhower, Jonathan Colmer, Mark Jacobsen, Chad Jones, Doug Gollin, Michael Greenstone, Kelsey Jack, Pete Klenow, Nick Ryan and seminar / conference participants at the AEA meetings, ASU, IGC Growth Week, the IMF, SED, UCSB, USC, Yale, and UCSD. For excellent research assistance we thank Qinzhuo Gong, Alejandro Nakab, and Shu Zhang. We are grateful to the IGC for financial support. All potential errors are our own. The views expressed herein are those of the authors and do not necessarily reflect the views of the National Bureau of Economic Research.

At least one co-author has disclosed a financial relationship of potential relevance for this research. Further information is available online at http://www.nber.org/papers/w27081.ack

NBER working papers are circulated for discussion and comment purposes. They have not been peer-reviewed or been subject to the review by the NBER Board of Directors that accompanies official NBER publications.

(C) 2020 by Stephie Fried and David Lagakos. All rights reserved. Short sections of text, not to exceed two paragraphs, may be quoted without explicit permission provided that full credit, including $(\odot$ notice, is given to the source. 
Electricity and Firm Productivity: A General-Equilibrium Approach

Stephie Fried and David Lagakos

NBER Working Paper No. 27081

May 2020

JEL No. E13,E23,O11,O41,Q43

\begin{abstract}
The lack of reliable electricity in the developing world is widely viewed by policymakers as a major constraint on firm productivity. Yet most empirical studies find modest short-run effects of power outages on firm performance. This paper builds a dynamic macroeconomic model to study the long-run general equilibrium effects of power outages on productivity. The model captures the key features of how firms acquire electricity in the developing world, in particular the rationing of grid electricity and the possibility of self-generated electricity at higher cost. Power outages lower productivity in the model by creating idle resources, by depressing the scale of incumbent firms and by reducing entry of new firms. Consistent with the empirical literature, the model predicts that the short-run partial-equilibrium effects of eliminating outages are small. However, the long-run general-equilibrium effects are many times larger, supporting the view that eliminating outages is an important development objective.
\end{abstract}

\author{
Stephie Fried \\ Arizona State University \\ sdfried@asu.edu \\ David Lagakos \\ Department of Economics, 0508 \\ University of California, San Diego \\ 9500 Gilman Drive \\ La Jolla, CA 92093 \\ and NBER \\ lagakos@ucsd.edu
}




\section{Introduction}

Most firms in the developing world put inadequate electricity supply at or near the top of their list of constraints holding back their productivity (World Bank Group, 2017). Not surprisingly then, improving electricity provision has emerged as a top policy priority for many developing countries to promote economic growth. Yet most existing empirical studies of the effects of power outages on firm productivity have found fairly modest impacts. For example, Allcott, Collard-Wexler, and O'Connell (2016) estimate that Indian manufacturing firms operate at a mere 1.5 percent lower productive level on average due to the (widespread) electricity outages they face. Similar studies also find that power outages lead to small declines in firm productivity across a broad set of developing countries. ${ }^{1}$ More generally, a growing micro literature on the effects on electrification has found small economic impacts, at least in rural areas (Dinkelman, 2011; Burlig and Preonas, 2016; Lee, Miguel, and Wolfram, Forthcoming). Given the massive differences in aggregate output per capita across countries (Hall and Jones, 1999; Caselli, 2005), these modest estimated effects of electricity suggest that policy makers could be overemphasizing its importance in their development strategy.

One important limitation of most of the existing empirical studies of electricity and firm productivity is that they are restricted to studying the short-run partial-equilibrium effects of power outages. The goal of this paper is to understand the general-equilibrium effects of unreliable electricity on firm and aggregate productivity in the long run. To do so, we build a dynamic macroeconomic model that incorporates several key aspects of how electricity is provided in the developing world, and how firms respond to an unreliable electricity supply. First, electricity is a strong complement to capital in the production function and other inputs cannot be easily be substituted for electricity (Atkeson and Kehoe, 1999; Hassler, Krusell, and Olovsson, 2015; Casey, 2018). Second, electricity is provided through the grid at a low price but rationed, with unpredictable power outages occurring in equilibrium (see e.g. Burgess, Greenstone, Ryan, and Sudarshan, 2020). Third, some firms self-produce electricity using generators, though at a higher cost than electricity purchased from the grid. Finally, firms can choose not to enter the "modern" electricity-using sector at all, and instead operate a low-productivity "traditional" technology (as in Midrigan and Xu, 2014) that doesn't require electricity.

\footnotetext{
${ }^{1}$ Fisher-Vanden, Mansur, and Wang (2015) find a statistically insignificant effect of power outages on firm productivity in a panel of Chinese manufacturing firms. Abeberese, Ackah, and Asuming (2019) estimate a 10 percent productivity decrease from outages among small Ghanaian firms. Similarly, Hardy and McCasland (2019) estimate that outages lead to a 13 percent decrease in productivity for Ghanaian enterprises with no workers, though they find no effect on productivity for all other firms. Grainger and Zhang (2017) estimate that outages lead to productivity decreases of less than one percent among Pakistani manufacturing firms. Scott, Darko, Lemma, and Rud (2014) find small and generally insignificant correlations between the number of power outages a firm experiences and its labor productivity across a sample of six major developing economies.
} 
To analytically illustrate how power outages affect firm productivity, we first present a simple version of the model in which the probability of a power outage is exogenous. Power outages are unpredictable in the sense that firms know the probability that the power will be on, but they do not know when it will be on. These unpredictable outages create idle resources in equilibrium. In particular, when the power is off, modern firms idle productive capital if they do not have enough generator capital. When the power is on, modern firms instead idle their generator capital, because the marginal cost of self-generated electricity is higher than the price of grid electricity. We measure the short-run partial-equilibrium effect of eliminating power outages by simulating a counterfactual scenario under which firms make entry and scale decisions assuming that the probability of grid power is less than one, but then experience no outages ex-post. This exercise captures the spirit of the empirical literature described above which focuses on ceteris paribus regression counterfactuals, assuming that firms face no power outages, but that all else is constant. We show that eliminating outages increases output per worker in the short-run partial equilibrium only because productive capital is no longer idled. By contrast, we simulate the long-run general-equilibrium effect of eliminating outages by solving for a new steady state of the model in which firms get grid electricity with probability one. The long-run general-equilibrium effect includes the increases in output per worker from not idling productive capital, as in the short-run partial-equilibrium, plus two additional channels. First, the incumbent modern firms, who now expect never to idle capital in an outage again, demand more productive capital and zero generator capital. Since in steady state, the rental rate on capital is pinned down entirely by the household Euler equation, capital supply, rather than the price of capital, expands to meet the new demand from firms. Second, when there are no outages, more firms produce with the modern technology, which is more attractive now that grid electricity is reliably available.

To quantify the importance of eliminating power outages on firm and aggregate productivity, we extend the simple model to a richer quantitative version which endogenizes the probability of a power outage by adding a distorted electricity-production sector. We set the electricity price below its market-clearing value, as in the evidence of Burgess et al. (2020), which leads electricity producers to restrict supply. Thus, instead of the price clearing the electricity market, the extent of power outages is determined so that the rationed supply of grid electricity equals the demand at the regulated price. We calibrate the model to match the main features of electricity use in five large Sub-Saharan African countries. The key targets to inform our quantitative analysis are: the importance of electricity in production, the cost of generator electricity versus grid electricity and the overall prevalence of self-generated electricity, including both the number of firms that have generators and how much electricity those firms self-produce. 
We use the calibrated model to simulate the long-run general-equilibrium effects of eliminating power outages on the macroeconomy. In each country, we compare outcomes in an undistorted steady state with no power outages to their values in the initial calibrated steady state, which has widespread outages. To compute the undistorted steady state, we remove the electricity price regulations and allow the price to adjust freely to clear the electricity market. Our model predicts that the short-run partial-equilibrium effects are modest, on the order of a few percentage points. These small effects mirror the estimates from the microeconomic literature on electricity and firm productivity, lending credence to the model's short-run partial-equilibrium predictions. In contrast, the long-run general-equilibrium effects of eliminating power outages are around five times larger, averaging 25 percent across our countries. ${ }^{2}$ Through the lens of development accounting, eliminating power outages works through both higher aggregate capital per worker and higher measured TFP, as fewer resources are idled and production moves into the modern sector.

We conclude by providing new evidence that helps validate the model's long-run aggregate predictions, which are harder to test in practice. In particular, we conduct new surveys of firms in Nigeria and Ghana about the expected effects of permanently eliminating power outages. The majority of Ghanaian and Nigerian firms report that eliminating outages would be likely or very likely to expand their own investment and hiring, consistent with the model's firmexpansion channel. An even larger fraction of firms in both countries expect that permanently eliminating power outages would lead to entry of new firms into their industry, just as the model's firm-entry channel predicts. As a frame of reference, we also surveyed firms from the same population about the likely effects of a placebo "treatment" in which the national airports convert to solar power, on the exact same outcomes. Across both countries and all questions, the expected effects of eliminating power outages are economically and statistically larger than the effects of the placebo, suggesting that our results are unlikely to be artifacts of misreporting by survey respondents.

Our paper builds on two distinct literatures in macroeconomics. The first is the growing macro development literature that draws on dynamic general equilibrium models to understand how the partial equilibrium effects of development policies- informed by reduced-form empirical evidence- compare to the long-run general equilibrium effects. Our quantitative exercises are particularly related to those of Buera, Kaboski, and Shin (2019), who use a macroeconomic

\footnotetext{
${ }^{2}$ These larger longer-run effects are similar in spirit to the literature on the long-run regional effects of electricity (Rud, 2012; Lipscomb, Mobarak, and Barham, 2013), who find large long-run differences in economic development across regions within countries with differing levels of electrification. Rud (2012) studies a panel of Indian states between 1965 and 1984, while Lipscomb et al. (2013) consider a panel of Brazilian states from 1960 to 2000.
} 
model of credit constrained firms to infer how the general equilibrium effects of microfinance lending differ from the partial equilibrium effects estimated in the empirical literature on micro finance. Also in this vein, Brooks and Donovan (Forthcoming) flush out the general-equilibrium effects of improved transportation infrastructure on rural farmers starting with reduced-form evidence on the effects of rural bridge building. Using a similar methodology, Lagakos, Mobarak, and Waugh (2020) quantify the aggregate effects of subsides to rural-urban migration, and Akcigit, Alp, and Peters (Forthcoming) infer the general equilibrium effects of improving managerial capabilities.

The second literature on which we build is the recent literature on sector linkages and development, which studies how low productivity in one intermediate sector - especially one that exhibits a high degree of complementarity with other sectors- can have a disproportionate effect on aggregate output per worker (Jones, 2011; Bartelme and Gorodnichenko, 2015; Baqaee and Farhi, 2019). ${ }^{3}$ Electricity is a classic example of such an input, and our paper is the first to study the general equilibrium implications of distortions in the electricity sector. We illustrate how the distortions in the electricity sector lead to larger aggregate gains than the general distortions analyzed by most studies in this literature because the artificially low electricity price depresses electricity supply relative to a competitive economy. Boehm and Oberfield (2018) focus on a different type of distortion stemming from a government inability to enforce contracts between firms, and study how that propagates through linked sectors. Liu (2019) builds a model in which distortions at the sector level accumulate through backward demand linkages, and that the most upstream sectors become the "sink" for market imperfections, which may well apply to electricity production, though this channel is not present in the current model. Baqaee and Farhi (2020) show that sectoral shocks in a distorted economy, such as ours, can be far more potent than in an efficient one, since moving resources out of a distorted sector can have first-order effects on output. ${ }^{4}$

\footnotetext{
${ }^{3}$ Most of this literature has focused on business cycle fluctuations, rather than long-run outcomes, and has largely concluded that input-output linkages play an important role in amplifying short-run microeconomic shocks; see Carvalho (2014) for an insightful overview of the literature. Empirically, di Giovanni, Levchenko, and Méjean (2014) draw on rich firm-level data to document that firm-specific shocks contribute to aggregate fluctuations mainly through firm-to-firm linkages. Similarly, Atalay (2017) shows that outputs at the sector level are strong complements, implying that shocks to individual sectors have out sized aggregate impacts.

${ }^{4}$ Additionally, our paper relates to the literature that studies general equilibrium models of energy use and the macroeconomy (see e.g. Hassler, Krusell, and Smith, Jr., 2016, for an overview). Much of this literature focuses on the macroeconomic and environmental impacts of a carbon tax. Previous studies explore these impacts in a variety of different settings, including neoclassical growth frameworks, (e.g., Golosov, Hassler, Krusell, and Tsyvinski, 2014; Barrage, 2019; Fried, Novan, and Peterman, 2018) and models of endogenous innovation (e.g., Acemoglu, Aghion, Bursztyn, and Hémous, 2012; Hémous, 2016; Casey, 2018; Fried, 2018; Lemoine, 2018). A common theme is that there is an important role for energy in the production function, though we abstract from environmental factors.
} 


\section{Electricity and Firms in the Developing World: Stylized Facts}

To motivate our model of electricity and firm productivity, we begin by summarizing four key facts about electricity in developing countries. To be sure, these facts are known by those who study electricity in developing countries, though they are likely to be less well known by macroeconomists. First, grid electricity is rationed to firms through frequent and unpredictable power outages. Second, some firms use generators to produce their own electricity to insure themselves against grid electricity shortages. Third, the cost to firms of self-generated electricity is substantially higher than the cost of grid electricity. Fourth, the electricity sector itself is highly distorted, with prices held at below-market levels in most countries.

\subsection{Firms Experience Frequent Unpredictable Power Outages}

Unlike in advanced economies, the electricity grid is highly unreliable in developing countries. Even firms with grid connections still experience frequent and unpredictable power outages (see e.g., Eberhard, Rosnes, Shkaratan, and Vennemo 2011; Scott et al. 2014). To illustrate how frequent power outages are in the developing world, we draw on evidence from the World Bank's World Enterprise Surveys (WES), which cover random samples of medium and large firms from a large set of countries (though the richest countries are excluded).

Figure 1 plots the percent of firms in the WES that report having experienced an electricity outage in the last month against GDP per capita. Each point on the graph represents the averages for all firms sampled in the WES by country in the most recent available year. The figure presents a very stark picture of how common electricity outages are in the developing world. In most of the word's poorest countries, more than eight out of ten firms experienced an outage in the last month. Across all countries in the data, the average percent of firms experiencing outages is 55 percent. There is also a clear negative relationship with outages and GDP per capita; nearly all the firms in the poorest countries experienced outages in the last month, but only one quarter of the firms experienced outages in the WES countries with the highest GDP per capita. The world's richest countries are not covered by the WES, but it is well-known that outages there are extremely infrequent. Power outages are, in other words, almost a defining feature of developing economies.

\subsection{Some Firms Self-Generate Electricity to Insure Against Outages}

Since electricity outages are clearly undesirable for firms, many of them self-produce electricity using generators (Alby, Dethier, and Straub 2013; Eberhard et al. 2011; Foster and Steinbuks 2008). The ability to self-produce electricity allows firms access to electricity during an outage, 
Figure 1: Percent of Firms Experiencing Electricity Outages

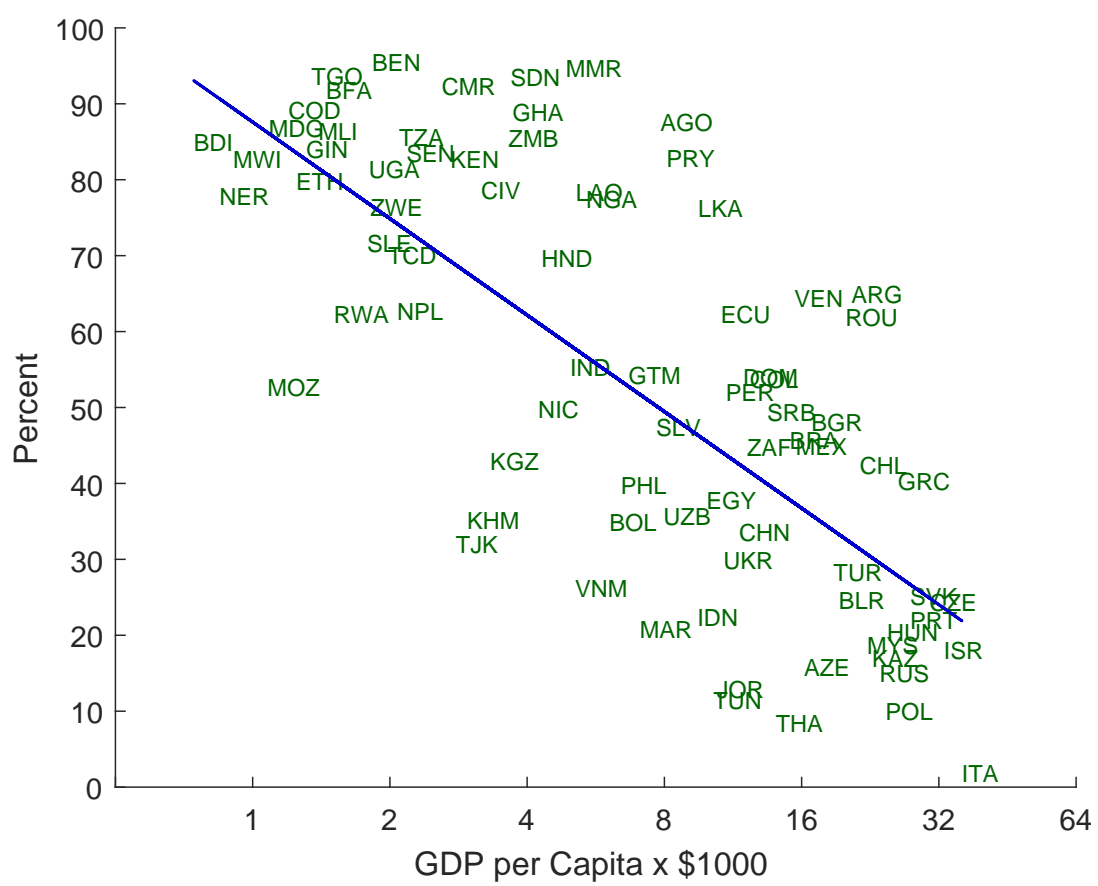

Note: This figure plots the percent of firms in the World Bank's World Enterprise Surveys that experienced an electricity outage in the last month against 2013 GDP per capita. The figure includes all countries with a population greater than five million and a survey covering at least one hundred firms.

which must be valuable given the frequency of outages. To see how much self-generation goes on in practice in the developing world, we turn again to the WES, at least for evidence on self-generation among the relatively large firms that make up the WES sample. We focus on a set of ten large African countries for which we have comparable data on other dimensions, which we discuss below.

Figure 2 plots the percent of firms in the WES that own or share a generator at the time of the survey in these ten countries. The generator ownership rate is 48 percent on average across these countries. Nigeria, which is Africa's largest economy, has the highest generator ownership rate, at 71 percent. Madagascar has the lowest rate at 19 percent. When looking across all countries in the WES, there is a strong negative correlation between generator ownership and GDP per capita, with less than 10 percent of firms in the richest WES countries owning generators. Thus, it is clear that many firms in the developing world use generators to insure themselves against outages, though far from all firms have access to generators 
Figure 2: Percent of Firms Owning or Sharing a Generator

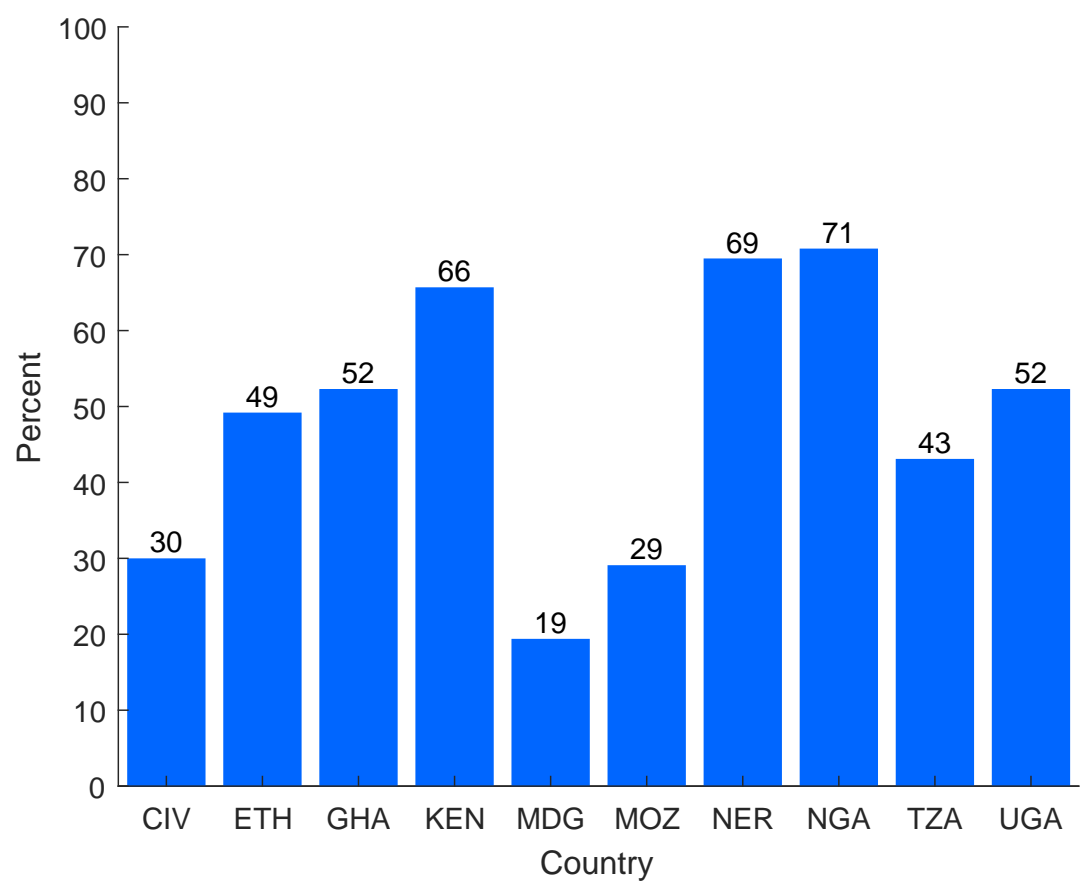

Note: This figure plots the percent of firms that own or share a generator in the ten most populous countries in Sub-Saharan Africa that have the data required for both Figures 2 and 3. The data on generator access are from the World Bank's World Enterprise Surveys.

\subsection{Self-Generated Electricity is More Expensive Than Grid Electricity}

Even though firms can produce their own electricity, this does not mean that firms are indifferent between getting their electricity from the grid or producing it themselves using generators. Evidence shows that self-generated electricity is substantially more costly for firms than grid electricity (Foster and Steinbuks, 2008).

Figure 3 plots estimates of the average cost of grid electricity and self-generated electricity in the ten largest Sub-Saharan African countries for which data are available. The average cost of self-generated electricity includes the capital costs of owning a generator, based on estimates in World Bank (2007), plus the cost of fuel for the generator (see Appendix B.2 for details on these calculations).

The average cost of self-generated electricity ranges from a low of $\$ 0.34$ per $\mathrm{kWh}$ in Ethiopia to a high of $\$ 0.45$ per $\mathrm{kWh}$ in Mozambique (reflecting differences in the price of fuel). Grid electricity prices range from $\$ 0.04$ per $\mathrm{kWh}$ in Ethiopia to $\$ 0.17$ per $\mathrm{kWh}$ in Uganda (Trimble, Kojima, Arroyo, and Mohammadzadeh, 2016). The variation in the grid electricity price likely reflects differences in official tariffs as well as differences in bill collection rates and theft. On average, self-generated electricity is approximately four times as expensive as grid electricity. 
Figure 3: Average Cost of Electricity: Grid vs. Generator

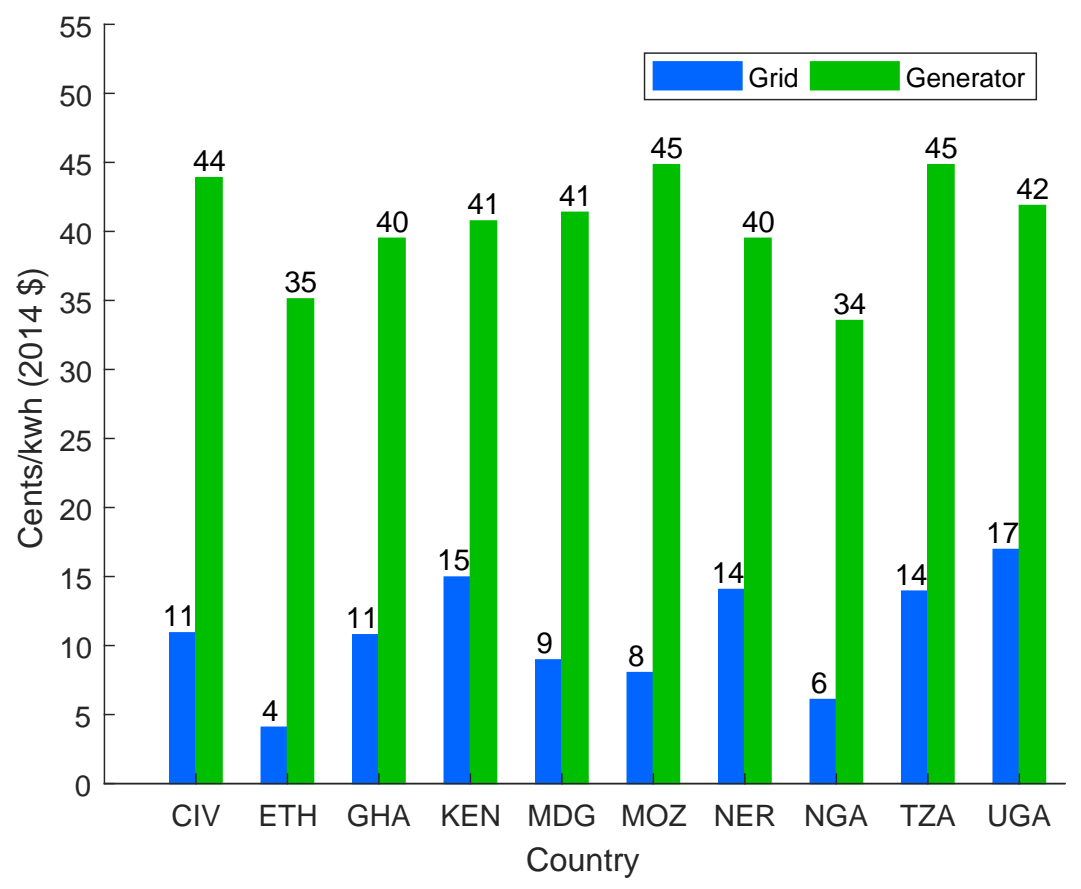

Note: This figure plots the effective price of grid electricity and the average cost of self-generated electricity in the ten most populous countries in Sub-Saharan Africa for which data are available. Data on the effective price of grid electricity, accounting for theft and lapses in bill collection, are from Trimble et al. (2016). We calculate the average cost of generator electricity from estimates of the capital cost of a typical diesel generator from World Bank (2007) and the price of diesel fuel. See Appendix B.2 for a full description.

Importantly, the high average cost of self-generated electricity results from both the high cost of the generator equipment and the high cost of the fuel necessary to run it. The marginal cost of self-generated electricity, which depends on the price of diesel fuel and the efficiency of the generator, is on average three times higher than the price of grid electricity. Thus, while firms with generators do have the ability to produce their own power during an outage, the cost of their electricity inputs are substantially higher when they self-produce, than when they directly purchase electricity from the grid.

\subsection{Grid Electricity Provision is Highly Distorted}

It is well known that the public sector regulates electricity providers in most countries. The developing world provides few exceptions to this rule. Moreover, as Trimble et al. (2016) document, virtually none of the electricity sectors in Sub-Saharan Africa collect enough revenue to recover their costs. One reason for this is the low official tariffs for electricity. Burgess et al. (2020) argue that governments in developing countries present electricity as a basic right for their citizens, and, as a result, political incentives play a substantial role in keeping electricity prices regulated at levels that are unprofitable for power producers. 
A second, related, reason that electricity prices are so low is the rampant non-payment that prevails throughout the developing world (see Jack and Smith, 2015). As Burgess et al. (2020) colorfully illustrate, power producers in the power sectors of Bihar, India have an official rate of $\$ 0.10$ per $\mathrm{kWh}$, which should, in principle, be enough to cover their production cost of about $\$ 0.06$ per $\mathrm{kWh}$. Yet power producers collect only around $\$ 0.01$ per $\mathrm{kWh}$ after subsidies, technical losses, un-billed power and unpaid bills are taken into consideration! While the numbers differ in Africa, the problems are largely similar: technical losses, un-billed power and underpayment all cut into the effective prices of grid electricity (Eberhard et al. 2011; Jack and Smith 2015; Dzansi, Puller, Street, and Yebuah-Dwamena 2018).

In sum, the price of grid electricity is regulated to be too low across the developing world, and this regulation is the proximate cause of the widespread power outages there (Burgess et al., 2020; Eberhard et al., 2011). Some firms can insure against these outages by producing their own electricity with generators. However, the self-generation of electricity is expensive because both the average and marginal cost of self-generated electricity are considerably higher than the effective price of grid electricity.

\section{Simple Model of Electricity and Firm Productivity}

We now build a simple, dynamic, general-equilibrium model that incorporates the key features of electricity supply in developing countries presented in the previous section. The model is intentionally stylized to provide an analytic characterization of how power outages impact firm productivity in general equilibrium. In particular, the model takes the probability of grid power as exogenous, abstracts from hired labor input and assumes that the price of grid electricity is zero. We relax all of these assumptions in Section 4 to follow.

\subsection{Environment}

The economy is inhabited by a representative household that chooses consumption and saving each period to maximize:

$$
\sum_{t=0}^{\infty} \beta^{t} u\left(C_{t}\right)
$$

where $\beta \in(0,1)$ is the discount factor, $C_{t}$ is consumption, and $u(\cdot)$ is a concave, strictly increasing and continuously differentiable period utility function. Households save in physical 
capital. Capital accumulates according to the standard law of motion:

$$
K_{t+1}=(1-\delta) K_{t}+I_{t}
$$

where $\delta \in[0,1]$ is the depreciation rate and $I_{t}$ is the number of final goods saved as investment. Households rent capital to firms at rate $R_{t}$. Household income includes the payments to capital and profits from the firms (described below).

There is a unit measure of heterogeneous entrepreneurs that operate firms and produce a homogeneous final good using their managerial ability and capital input. Each entrepreneur draws her managerial ability, $z$, from distribution $G(z)$ with support $z \in[1, \infty]$. Entrepreneurs can choose to operate either in the "traditional sector" or in the "modern sector". The sectors differ in terms of their production technologies and associated input requirements. If the entrepreneur chooses to operate in the modern sector, she must pay an entry cost, $\Omega$.

The production function in the traditional sector is:

$$
y_{t}^{T}=z^{1-\eta}\left[k_{t}^{T}\right]^{\eta},
$$

where $y_{t}^{T}$ is output of the final good, $k_{t}^{T}$ is the capital input and $\eta \in[0,1]$ measures the entrepreneur's span of control. The traditional entrepreneur chooses capital to maximize profits, $\pi^{T}$, where profits are the difference between production and rental payments for capital.

The production technology in the modern sector differs from that of the traditional sector in two ways. First, it uses managerial and capital inputs more efficiently. Second, it requires electricity. As discussed in Section 2, the supply of grid electricity is rationed and unpredictable, meaning frequent power outages. To incorporate this unpredictable rationing into the model, we divide the time period into a continuum of measure one of "instants." We model the availability of grid power in each instant $i$ of period $t$ as the realization of an exogenous random variable: with probability $v$, grid power is available in instant $i$ and with probability $1-v$, grid power is not available. As such, $v$ corresponds to the fraction of the period that the power is on and $1-v$ corresponds to the fraction of the period that the power is off.

Following Hassler et al. (2015), the modern firm's output in each instant $i, y_{i t}^{M}$, is a Leontief function between capital and electricity:

$$
y_{i t}^{M}=A^{M} z^{1-\eta}\left[\min \left(k_{t}^{M}, e_{i t}\right)\right]^{\eta},
$$

where $e_{i t}$ is the electricity that the firm uses during instant $i$ to operate her capital input, and $A^{M}$ is the TFP in the modern sector. We require that $A^{M}>\left[(1-\gamma) v^{1 /(1-\eta)}\right]^{-1 /(1-\eta)}$, which 
ensures that entrepreneurs operate in both sectors in equilibrium. When capital and electricity inputs are equated, the production function equals $A^{M} z^{1-\eta}\left[k_{t}^{M}\right]^{\eta}$, mirroring the production function in the traditional sector, but with higher productivity.

All instants when grid power is on are symmetric and all instants when grid power is off are symmetric. Let $y_{1 t}^{M}$ denote output during any instant when the power is on and $y_{0 t}^{M}$ denote output during any instant when the power is off. The firm's total output in period $t, y_{t}^{M}$, equals the sum of output during the instants when grid power is on and output during the instants when grid power is off:

$$
y_{t}^{M}=v y_{1 t}^{M}+(1-v) y_{0 t}^{M}
$$

There are two ways a modern firm can acquire electricity in each instant. First, if available, it can get it from the electricity grid, $e_{i t}^{G}$, at a "below-market" price that we set to zero for simplicity. Second, a fraction of modern firms can produce their own electricity, $e_{i t}^{S}$, at a higher cost. As discussed in Section 2, many, but not all, modern firms in low-income economies have access to generators. Some modern firms might not have generators because of financing constraints, lack of markets for generators, poor distribution networks for diesel fuel, or lack of parts or repair facilities (Scott et al., 2014). We do not take a stand on why some modern firms do not have generator access. Instead, we assume that a fraction $\gamma$ of modern firms have access to generators and a fraction $1-\gamma$ do not. An entrepreneur learns if she has generator access after she enters the modern sector. Importantly, while generator access grants the firm the ability to rent a generator and produce its own electricity, it does not require the firm to do so. Firms with generator access endogenously decide how much electricity to self-produce, if any.

Grid and self-generated electricity are perfect substitutes in the production of the final good. For example, if a machine requires five kilowatt-hours of electricity to operate, it does not matter if those kilowatt-hours are produced by a diesel generator or by a coal-fired power plant. To generate its own electricity in instant $i$, the firm combines self-generation capital, $k_{t}^{S}$, with fuel, $f_{i t}$ (denominated in units of final good), according to:

$$
e_{i t}^{S}=\min \left[k_{t}^{S}, f_{i t}\right]
$$

The marginal cost of a unit of grid electricity is one unit of the final good, which is used as fuel for the generator. Since all instants without power are symmetric, we use the notation $f_{0 t}$ to denote the firm's demand for fuel during any instant without power. 
Power outages in the model correspond to instants when the power is off and the firm produces $y_{0 t}$. The direct effect of these outages for firms with generators is that they must self-produce all of their electricity inputs. If they do not have enough generator capital to operate their productive capital at full capacity, then they must idle some productive capital, partially halting production. The direct effect of outages for firms without generators is to halt all production. In practice, power outages often require halting production because they lead to assembly line disruptions, failure of electrically operated machines, and loss of lighting (Scott et al., 2014).

\subsection{Modern Firm's Problem}

We first describe the optimization problem for modern firms with generator access. At the start of period $t$, each modern firm chooses its capital input, $k_{t}^{M}$, and generator capital, $k_{t}^{S}$, both of which are then fixed for the entire period. During each instant, the firm chooses its electricity input. If the grid power is on, the firm gets electricity from the grid (since it has zero marginal cost). If the grid power is off, the firm either produces its own electricity or simply idles its capital input. The firm's profits are the difference between production and the costs of generator capital, productive capital and fuel:

$$
\pi_{t}^{M}=v y_{1 t}^{M}+(1-v)\left(y_{0 t}^{M}-f_{0 t}\right)-R_{t}\left(k_{t}^{S}+k_{t}^{M}\right) .
$$

Importantly, the firm only pays for fuel during instants when the power is off. In contrast, the firm must rent the generator and productive capital for the entire period. Since power outages are unpredictable, as discussed in Section 2, firms cannot rent a generator only when the power is off, or productive capital only when the power is on.

Profit maximization in the presence of power outages presents firms with a dismal trade-off. A firm can purchase enough generator capital to operate its productive capital at full capacity when the power is off. But then it must idle generator capital when the power is on. Alternatively, the firm can purchase less generator capital, and thus reduce its idle generator capital when the power is on. But then it must idle some of its productive capital when the power is off.

Formally, the modern firm's problem is to choose $k_{t}^{M}, k_{t}^{S}, e_{1 t}^{G}$, and $f_{0 t}$ to maximize profits, taking the probability of grid power, $v$, and the rental rate of capital, $R_{t}$, as given. The Lagrangian for the firm's problem can be written as:

$$
\begin{gathered}
\mathscr{L}=v A^{M} z^{1-\eta}\left(k_{t}^{M}\right)^{\eta}+(1-v)\left(A^{M} z^{1-\eta}\left(k_{t}^{S}\right)^{\eta}-k_{t}^{S}\right) \\
-R_{t}\left(k_{t}^{S}+k_{t}^{M}\right)+\theta\left(k_{t}^{M}-k_{t}^{S}\right),
\end{gathered}
$$


where $\theta$ represents the Lagrange multiplier on the inequality constraint that $k_{t}^{S} \leq k_{t}^{M}$. This inequality constraint arises from the firm's trade-off between idling productive capital and idling generator capital. In particular, it is never optimal to produce more self-generated electricity than is required to operate the productive capital, implying that generator capital will never exceed productive capital, i.e. $k_{t}^{S} \leq k_{t}^{M}$. However, it could be optimal to hold less generator capital than is necessary to operate the productive capital at full capacity when the power is off, i.e. $k_{t}^{S}<k_{t}^{M}{ }^{5}$

The optimization problem for modern firms without generator access is similar to the above discussion except that generator capital always equals zero. Hence, the firm must idle all of its productive capital input during an outage, implying that its profits equal equation (7) with the self-generation terms set to zero: $y_{0 t}=f_{0 t}=k_{t}^{S}=0$.

We now characterize how the availability of grid power, $v$, affects modern firms' optimal levels of productive capital and of generator capital (for those firms with generator access).

Proposition 1. The firm's productive capital input is increasing in the probability of grid electric$i t y, v$, for any $R_{t}$. Firms with generator access idle generator capital when the power is on for any $v<1$. For these firms, there exists a cutoff $v^{*}\left(R_{t}\right) \in(0,1)$ such that when $v<v^{*}\left(R_{t}\right)$, generator capital is increasing in $v$ and no productive capital is idled. When $v \geq v^{*}\left(R_{t}\right)$, generator capital is decreasing in $v$ and productive capital is idled when the power is off. Generator capital equals zero when $v=1$.

Figure 4 illustrates the implications of Proposition 1 for optimal production by modern firms with a given productivity, $z$. The green solid line and the green o's plot production by modern firms with generator access during instants when the power is on and off, respectively. Similarly, the blue dashed line and the blue x's plot production by modern firms without generator access during instants when the power is on and off. Moving from left to right on the x-axis increases the probability of grid power from zero (no grid power) to one (no outages). The value $v^{\star}$ corresponds to the threshold in Proposition 1 , beyond which firms with generators choose to idle some productive capital during an outage.

We focus first on the production decisions by the firms with generator access (green solid line and o's). When $v<v^{\star}$, firms operate their productive capital at full capacity when the power is off, implying that output is the same during instants with and without grid power. When

\footnotetext{
${ }^{5}$ By contrast, the other Leontief production functions - (4) when the power is on, and (6) when the power is off - both hold with equality. That is, $f_{0 t}=k_{t}^{S}$, since it is never optimal to purchase more or less fuel than is necessary to operate the generator capital at full capacity when the power is out, and $e_{0 t}^{G}=k_{t}^{M}$, since it is never optimal to use more or less grid electricity than is necessary to operate the productive capital when the power is on.
} 
Figure 4: Solution to the Modern Firm's Problem

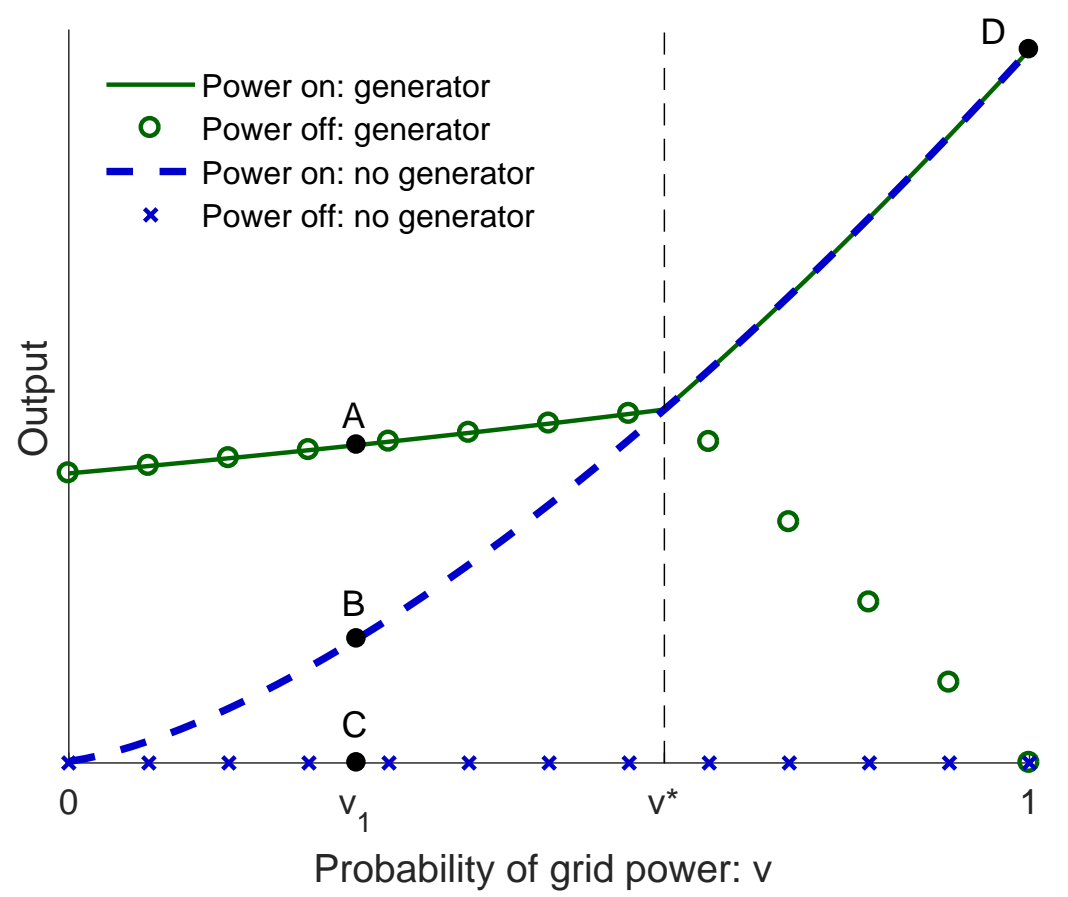

Note: The green solid line and o's plot production by a modern firm with generator access when the power is on and off, respectively. The blue dashed line and x's plot production by a modern firm without generator access when the power is on and off, respectively. Value $v^{\star}$ corresponds to the cutoff from Proposition 1.

$v>v^{\star}$, firms idle some of their productive capital when the power is off. As a result, output is lower when the power is off than when the power is on. When $v>v^{\star}$, output when the power is off decreases with $v$ because firms rent less generator capital as the probability of grid power increases. The intuition is that when $v$ is high, outages are sufficiently rare such that it is optimal for firms to idle some of their productive capital during the occasional outage.

We turn next to the firms without generator access. Regardless of the probability of grid power, these firms cannot produce when the power is off, hence the blue x's always equal zero. When the power is on and $v<v^{\star}$, output produced by firms without generator access is less than output produced by firms with generator access (e.g. the dashed blue line is below the solid green line). The marginal product of productive capital is lower for firms without generator access because they must idle this capital for fraction $1-v$ of the period. As a result, they rent less productive capital and thus produce less output when the power is on. In contrast, when $v \geq v^{\star}$, output produced by firms with and without generator access is equal during instants with grid power. In this region, the marginal product of productive capital is the same for firms with and without generator access because both types of firms idle the marginal unit of productive capital when the power is off. 
Importantly, output when the power is on increases with the probability of grid power for all modern firms (e.g., the solid green and dashed blue lines are upward sloping). The reason is that increases in the probability of grid power increase the marginal product of productive capital because it is idled for a smaller fraction of the period (for modern firms without generators, and for all modern firms when $v>v^{\star}$ ) and because having access to grid power for a longer fraction of the period reduces the average cost of electricity over the period (for modern firms with generators). As a result, all modern firms scale up production by renting more productive capital. Additionally, note that among modern firms with generators, a marginal increase in the probability of grid power results in a larger increase in output when $v>v^{\star}$, than when $v<v^{\star}$ (e.g., the slope of the solid green line is steeper when $v>v^{\star}$ ). When $v<v^{\star}$, firms optimally choose to purchase enough generator capital to produce at full capacity when the power is off, implying that any increase in scale in response to an increase in $v$ requires more productive capital and more generator capital. In contrast, when $v>v^{\star}$, firms' optimal demand for generator capital falls with $v$. Thus, any increase in scale in response to an increase in $v$ in this region requires an increase in productive capital but a decrease in generator capital.

We define the short-run partial-equilibrium effect of eliminating outages as the increase in the firm's output when it learns that there will be no outages ex-post, after it has already made its long-term input decisions. This definition captures the spirit of the microeconomic literature on power outages and firm productivity which considers the effect of eliminating outages on firms who have already made their entry and scale decisions. We can use Figure 4 to understand the short-run partial-equilibrium effects of eliminating outages in the context of our model. For example, consider an economy with probability of grid power $v_{1}$. The short-run partialequilibrium effect of eliminating outages for firms without generator access is the increase in output when they produce at point B for the entire period, instead of switching between points $\mathrm{B}$ and $\mathrm{C}$. The short-run partial-equilibrium effect of eliminating outages for firms with generator access is zero because they produce at point A for the entire period, regardless of whether the power is on or off. Hence, all of the short-run partial-equilibrium gains in output per worker arise because firms without generator access no longer idle productive capital. However, eliminating outages in the short-run partial-equilibrium does not remove idle resources from the economy altogether because firms with generator access still rent generators, which they now idle for the entire period.

In addition to firms' short-run partial-equilibrium response to outages, Proposition 1 implies that eliminating outages causes existing modern firms to demand more productive capital and zero generator capital, all else constant. This increase in scale implies that not only do the firms produce on the power-on line for the entire period, but they also incorporate that $v=1$ 
into their optimal production decisions by moving all the way to the right along the $\mathrm{x}$-axis in Figure 1. Consequently, eliminating outages (holding fixed $R_{t}$ ) increases output produced by modern firms with and without generator access to point $\mathrm{D}$ in the upper-right corner of Figure 4. Like the short-run partial-equilibrium effect, firms do not idle productive capital at point $D$ because the power is on for the entire period. But unlike the short-run partial-equilibrium effect, firms also do not idle generator capital at point $D$ because they know ex-ante that there will be no outages, and hence they do not rent any generator capital to begin with.

\subsection{Modern-Sector Entry}

Having characterized the optimal behavior of firms in the modern sector, we now turn to the decision of whether or not to enter the modern sector. The entrepreneur enters the modern sector if the expected value of profits in the modern sector minus the entry cost exceeds the value of profits in the traditional sector:

$$
E\left(\pi_{t}^{M}\right)-\Omega \geq \pi_{t}^{T}
$$

where the expectation is taken over whether not the entrepreneur has generator access. We show in Appendix A that as long as there exist entrepreneurs in both sectors, then the difference in expected profits, $E\left(\pi_{t}^{M}\right)-\pi_{t}^{T}$, is increasing in $z$. Thus all entrepreneurs with $z>z_{t}^{\star}$ enter the modern sector, where productivity cutoff $z_{t}^{\star}$ is the value of $z$ such that equation (9) holds with equality. This result implies that lower productivity entrepreneurs operate in the traditional sector and higher productivity entrepreneurs operate in the modern sector. Firm size increases with the entrepreneur's productivity, thus the smallest firms are traditional and the largest firms are modern.

\subsection{Definition of a Competitive Equilibrium}

We define a sequence-of-markets equilibrium for this economy. We denote whether a modern firm has generator access with indicator variable $x \in\{0,1\}$, where $x=1$ denotes generator access and $x=0$ denotes no access. A sequence-of-markets equilibrium consists of: a sequence of rental rates of capital, $\left\{R_{t}\right\}_{t=0}^{\infty}$; productivity cutoffs, $\left\{z_{t}^{\star}\right\}_{t=0}^{\infty}$; household allocations, $\left\{C_{t}, K_{t}\right\}_{t=0}^{\infty}$; and entrepreneurial allocations $\left\{k_{t}^{T}(z), k_{t}^{S}(1, z), k_{t}^{M}(x, z), e_{1 t}^{G}(x, z), f_{0 t}(1, z)\right\}_{t=0}^{\infty}$ for all $x \in\{0,1\}$ and for all $z \in[1, \infty]$ such that:

1. Given prices, allocations of entrepreneurs across the traditional and modern sectors are consistent with the modern-sector productivity cutoffs, $\left\{z_{t}^{\star}\right\}_{t=0}^{\infty}$, defined in equation (9).

2. Given prices, traditional-sector allocations solve the profit maximization problem for all 
firms in the traditional sector and modern-sector allocations solve the profit maximization problem for all firms in the modern sector.

3. Given prices and firm profits, household allocations maximize (1) subject to the budget constraint:

$C_{t}+K_{t+1}=R_{t} K_{t}+(1-\delta) K_{t}+\int_{1}^{z_{t}^{\star}} \pi_{t}^{T}(z) d G(z)+\int_{z_{t}^{\star}}^{\infty}\left(\gamma \pi_{t}^{M}(1, z)+(1-\gamma) \pi_{t}^{M}(0, z)-\Omega\right) d G(z)$

and the non-negativity constraints, $C_{t} \geq 0$, and $K_{t} \geq 0$, where $\pi_{t}^{T}(z)$ are the profits of the traditional firms with productivity $z, \pi_{t}^{M}(x, z)$ are the profits of the modern firms with generator access, $x$, and productivity $z$.

4. The market for capital clears:

$$
K_{t}=\int_{1}^{z_{t}^{\star}} k_{t}^{T}(z) d G(z)+\int_{z_{t}^{\star}}^{\infty}\left(\gamma k_{t}^{M}(1, z)+(1-\gamma) k_{t}^{M}(0, z)+\gamma k_{t}^{S}(1, z)\right) d G(z) .
$$

We are interested primarily in how eliminating outages effects the economy in the long-run. For this it is useful to define a steady state competitive equilibrium, which consists of a constant rental rate, $R$; productivity cutoff $z^{\star}$; household allocations, $\{C, K\}$; and entrepreneurial allocations $\left\{k^{T}(z), k^{S}(1, z), k^{M}(x, z), e_{1}^{G}(x, z), f_{0}(1, z)\right\}$ for all $x \in\{0,1\}$ and for all $z \in[1, \infty]$ such that conditions (1)-(4) hold and all variables are constant from one period to the next.

\subsection{Long-Run General-Equilibrium Effects of Power Outages}

We define the long-run general-equilibrium effect of eliminating outages as the steady state increase in aggregate output (and other equilibrium variables) when we increase the probability of grid power from its existing value to one. We first characterize how the probability of grid power affects entry into the modern sector in the long-run general equilibrium.

Proposition 2. The steady-state productivity cutoff, $z^{\star}$, is decreasing in the probability of grid power, $v$.

Proof: The household's first order condition for capital implies that the steady-state rental rate is:

$$
R=\frac{1}{\beta}+\delta-1
$$


and hence the steady-state price of capital does not depend on the probability of grid power. It follows that an increase in $v$ does not affect profits for a traditional firm. Therefore, we only need to show that expected profits for a potential modern entrant with a given $z$ are increasing in $v$. By the envelope theorem:

$$
\frac{\partial E\left(\pi^{M}(z)\right)}{\partial v}=\gamma\left[y_{1}^{M}(1, z)-y_{0}^{M}(1, z)+f_{0}(1, z)\right]+(1-\gamma) y_{1}^{M}(0, z)
$$

Note that the expectation is taken over $x$, the indicator variable which determines if the firm has generator access. If $v<v^{\star}$, then firms with generator access operate at full capacity when the power is off, implying that $y_{0}^{M}(1, z)=y_{1}^{M}(1, z)$. When $v>v^{\star}, y_{1}^{M}(1, z)>y_{0}^{M}(1, z)$. In either case, equation (12) is positive, implying that $E\left(\pi^{M}(z)\right)$ is increasing in $v$.

Our analytic model allows us to compare the short-run partial-equilibrium effect of eliminating outages with the long-run general-equilibrium effect. The short-run partial-equilibrium effect corresponds to the increase in aggregate output when power outages are eliminated expost. The long-run general-equilibrium effect incorporates the effects of two additional channels. First, since the steady-state rental rate is pinned down by the household Euler equation, Proposition 1 implies that all existing modern firms scale up their production by demanding more productive capital and reducing their demand for generator capital to zero. We call this the firm-expansion channel. Second, Proposition 2 implies that more entrepreneurs enter the modern sector, increasing modern output and decreasing traditional output. We call this the firm-entry channel. A key difference between the short-run partial-equilibrium and the longrun general-equilibrium effects is that the long-run general-equilibrium effect accounts for the fact that permanently eliminating outages changes firms' expectations and hence their behavior with regards to entry and their scale of operation, represented by their choices of productive and generator capital.

Proposition 3. For any $v<1$, the long-run general-equilibrium effect of eliminating outages is larger than the short-run partial-equilibrium effect.

Proof: We define steady state A to be the steady state of the economy when the probability of grid power is $v_{a}<1$. We use this steady state as a baseline from which to calculate the short-run partial-equilibrium and long-run general-equilibrium effects of eliminating outages. The first order conditions from the traditional firm's profit maximization problem imply that capital demand for a traditional firm with productivity, $z$ in steady state A equals:

$$
k_{a}^{T}(z)=z\left(\frac{\eta}{R}\right)^{\frac{1}{1-\eta}}
$$


Similarly, the first order conditions from the modern firm's profit maximization problem imply that productive capital demand for a modern firm with generator access $x \in\{0,1\}$ and productivity $z$ in steady state A equals:

$$
k_{a}^{M}(0, z)=z\left(\frac{v_{a} \eta A^{M}}{R}\right)^{\frac{1}{1-\eta}} \quad \text { and } \quad k_{a}^{M}(1, z)= \begin{cases}z\left(\frac{\eta A^{M}}{2 R+1-v_{a}}\right)^{\frac{1}{1-\eta}} & : v_{a} \leq v^{\star}(R) \\ z\left(\frac{v_{a} \eta A^{M}}{R}\right)^{\frac{1}{1-\eta}} & : v_{a}>v^{\star}(R) .\end{cases}
$$

Demand for generator capital by a modern firm with generator access and productivity $z$ equals:

$$
k_{a}^{S}(1, z)= \begin{cases}z\left(\frac{\eta A^{M}}{2 R+1-v_{a}}\right)^{\frac{1}{1-\eta}} & : v_{a} \leq v^{\star}(R) \\ z\left(\frac{\left(1-v_{a}\right) \eta A^{M}}{R+1-v_{a}}\right)^{\frac{1}{1-\eta}} & : v_{a}>v^{\star}(R) .\end{cases}
$$

Let $z_{a}^{\star}$ denote the equilibrium productivity cutoff in steady state A. To calculate aggregate output, we substitute the above expressions for capital demand in each sector into the respective production functions (equations (3) and (4)) and integrate over the distribution of entrepreneurs. Aggregate output in the traditional, $Y_{a}^{T}$, and modern, $Y_{a}^{M}$, sectors equals:

$$
\begin{gathered}
Y_{a}^{T}=\left(\frac{\eta}{R}\right)^{\frac{\eta}{1-\eta}} \int_{1}^{z_{a}^{\star}} z d G(z) \text { and } \\
Y_{a}^{M}=\left\{\begin{array}{l}
{\left[\gamma A^{M}\left(\frac{A^{M} \eta}{2 R+1-v_{a}}\right)^{\frac{\eta}{1-\eta}}+(1-\gamma) v_{a} A^{M}\left(\frac{v_{a} \eta A^{M}}{R}\right)^{\frac{\eta}{1-\eta}}\right] \int_{z_{a}^{\star}}^{\infty} z d G(z) \quad: v_{a} \leq v^{\star}(R)} \\
{\left[v_{a} A^{M}\left(\frac{v_{a} A^{M} \eta}{R}\right)^{\frac{\eta}{1-\eta}}+\gamma\left(1-v_{a}\right) A^{M}\left(\frac{\left(1-v_{a}\right) \eta A^{M}}{R+1-v_{a}}\right)^{\frac{\eta}{1-\eta}}\right] \int_{z_{a}^{\star}}^{\infty} z d G(z): v_{a}>v^{\star}(R) .}
\end{array}\right.
\end{gathered}
$$

Aggregate output, $Y_{a}$, equals the sum of aggregate output in the traditional and modern sectors: $Y_{a}=Y_{a}^{T}+Y_{a}^{M}$.

We compute the short-run partial-equilibrium effect of eliminating outages. Define $\tilde{Y}$ to equal aggregate output when $v=1$, but the productivity cutoff equals its value when $v=v_{a}\left(z_{a}^{\star}\right)$ and 
the demands for capital equal their values when $v=v_{a}$ (equations (13) - (15)):

$$
\tilde{Y}=Y_{a}^{T}+ \begin{cases}{\left[\gamma A^{M}\left(\frac{A^{M} \eta}{2 R+1-v_{a}}\right)^{\frac{\eta}{1-\eta}}+(1-\gamma) A^{M}\left(\frac{v_{a} \eta A^{M}}{R}\right)^{\frac{\eta}{1-\eta}}\right] \int_{z_{a}^{\star}}^{\infty} z d G(z)} & : v_{a} \leq v^{\star}(R) \\ {\left[A^{M}\left(\frac{v_{a} A^{M} \eta}{R}\right)^{\frac{\eta}{1-\eta}}\right] \int_{z_{a}^{\star}}^{\infty} z d G(z)} & : v_{a}>v^{\star}(R) .\end{cases}
$$

The short-run partial-equilibrium effect of eliminating outages equals $\tilde{Y}-Y_{a}$. This represents the difference between output when firms choose their scale and sector but experience no outages ex-post and actual output.

To compute the long-run general-equilibrium effect of eliminating outages, we define steady state B to be the steady state of the economy when $v=1$. Let $z_{b}^{\star}$ be the equilibrium productivity cutoff in steady state B. Aggregate output in the traditional and modern sectors in steady state B equals:

$$
Y_{b}^{T}=\left(\frac{\eta}{R}\right)^{\frac{\eta}{1-\eta}} \int_{1}^{z_{b}^{\star}} z d G(z) \text { and } Y_{b}^{M}=A^{M}\left(\frac{A^{M} \eta}{R}\right)^{\frac{\eta}{1-\eta}} \int_{z_{b}^{\star}}^{\infty} z d G(z)
$$

Aggregate output in steady state B equals $Y_{b}=Y_{b}^{T}+Y_{b}^{M}$. The long-run general-equilibrium effect of eliminating outages equals $Y_{b}-Y_{a}$. This represents the difference between output in the steady state with no outages and output in the steady state with outages when the probability of grid power equals $v_{a}$.

To demonstrate that the long-run general-equilibrium effect of eliminating outages exceeds the short-run partial-equilibrium effect, we must show that $Y_{b}-Y_{a}>\tilde{Y}-Y_{a}$. First, note that by Proposition 2, the productivity cutoff in steady state B is less than the productivity cutoff in steady state $\mathrm{A}: z_{b}^{\star}<z_{a}^{\star}$. Then, since $A^{M}>\left[(1-\gamma) v^{1 /(1-\eta)}\right]^{-1 /(1-\eta)}>1$, it follows that:

$$
Y_{b}>\left(\frac{\eta}{R}\right)^{\frac{\eta}{1-\eta}} \int_{1}^{z_{a}^{\star}} z d G(z)+A^{M}\left(\frac{A^{M} \eta}{R}\right)^{\frac{\eta}{1-\eta}} \int_{z_{a}^{\star}}^{\infty} z d G(z) .
$$

We show that the right-hand-side of equation (19) is larger than the value of $\tilde{Y}$ defined in equation (18). First, observe that the first term on the right-hand-side of equation (19) equals $Y_{a}^{T}$. Second, one can show that the second term on the right-hand-side of equation (19) always exceeds the second term in equation (18). Therefore, it follows that $Y_{b}>\tilde{Y}$ which implies that $Y_{b}-Y_{a}>\tilde{Y}-Y_{a}$.

Figure 5 illustrates the implications of Proposition 3 for aggregate modern output, which is at 
Figure 5: Short-Run Partial-Equilibrium and Long-Run General-Equilibrium Effects of Outages

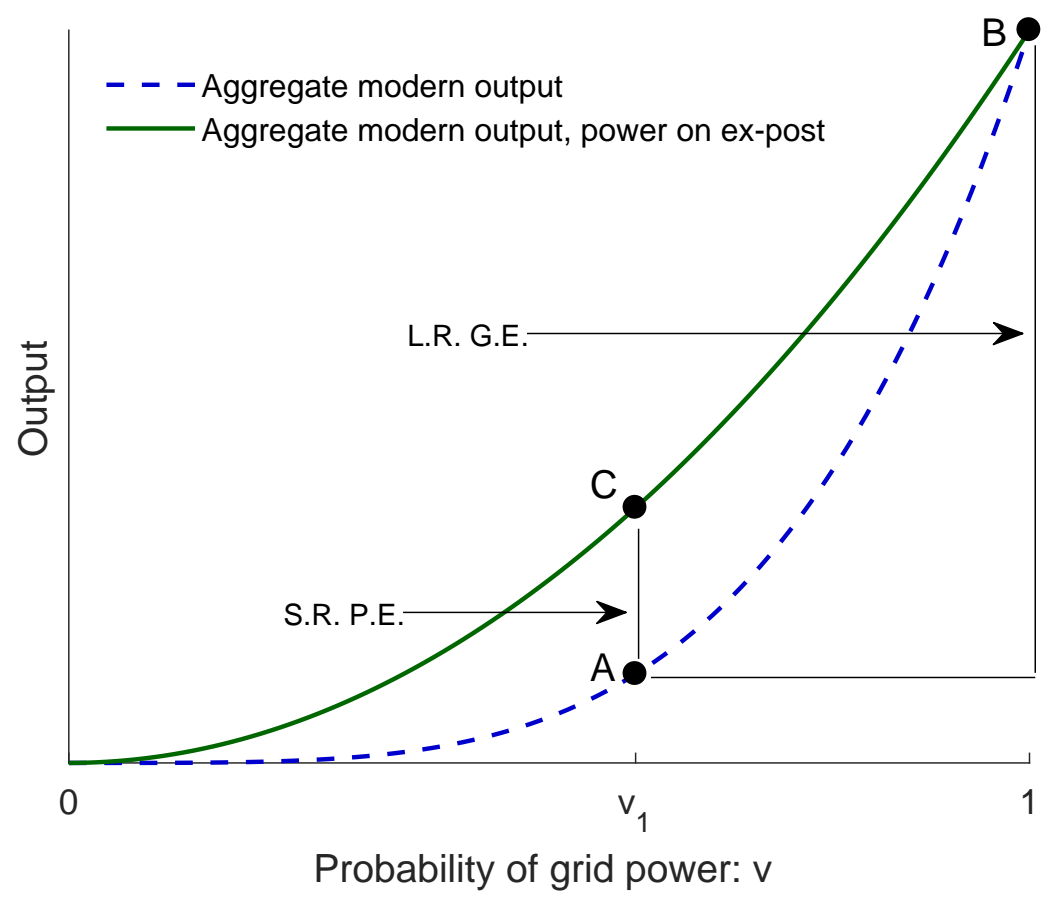

Note: The dashed blue line plots aggregate modern-sector output. The solid green line plots aggregate modern output when firms make their entry and scale decisions assuming the probability of grid power equals the value of $v$ on the $\mathrm{x}$-axis but the actual probability equals one. The short-run partial-equilibrium increase in aggregate modern output equals the vertical distance from $\mathrm{A}$ to $\mathrm{C}$ and the long-run general-equilibrium increase equals the vertical distance from A to B.

the heart of the proposition's result. The dashed blue line plots aggregate modern output as a function of the probability of grid power. Increases in the probability of grid power increase aggregate modern output through both the firm-expansion and the firm-entry channels. The solid green line plots aggregate modern output when outages are eliminated after firms have already made their capital and entry decisions.

To compare the short-run partial-equilibrium increase in aggregate modern output with the long-run general-equilibrium increase, consider an economy with probability of grid power, $v_{1}$. The short-run partial-equilibrium increase in aggregate modern output from eliminating outages is the increase from point A to point C. Point A corresponds to aggregate modern output when the probability of grid power equals $v_{1}$ and firms internalize this probability into their entry and capital decisions. Point $\mathrm{C}$ corresponds to aggregate modern output when firms make their entry and capital decisions assuming that the probability of grid power equals $v_{1}$, but the actual probability equals 1 . Aggregate modern output at point $\mathrm{C}$ is higher than at point A because firms produce on their power-on lines in Figure 4 for the entire period. In context of the proof of Proposition 3, moving from point A to point $\mathrm{C}$ is analogous to moving from $Y_{a}$ in steady state A to $\tilde{Y}$. 
The long-run general-equilibrium increase accounts for the effects of the firm-expansion and firm-entry channels by moving all the way to the right on the x-axis, increasing aggregate modern output from point A to point B. Graphically, the increase in aggregate modern output from $A$ to $B$ will always exceed the increase from $A$ to $C$ because the firm-expansion and firmentry channels imply that both lines must be upward sloping and they must be equal when $v=1$. Referring back to the proof of Proposition 3, moving from point A to point B parallels the move from $Y_{a}$ in steady state A to $Y_{b}$ in steady state B.

The overall lesson from the model is that looking only at the short-run effect of eliminating outages on firm productivity paints an incomplete picture of the total effect. In the longer run, firms anticipate that there will be no outages. As a result, they demand more productive capital and zero generator capital, scaling up their operations. New firms choose to operate with better, electricity-using, technologies. Combined, these two channels cause output per worker to rise more in the long-run than in the short-run.

\section{Quantitative Model and Calibration}

To quantify the long-run general-equilibrium effect of eliminating outages, we extend the model from Section 3 in ways that are useful for the numerical analysis, but leave the fundamental intuition unchanged. Most importantly, we model power outages as the economy's endogenous response to a regulated electricity price that the government fixes below the marketclearing level. As a result, the supply of grid electricity is less than the demand. The amount of rationing, and hence the probability of grid power, is determined so that the rationed demand for grid power equals the amount supplied at the regulated price.

Additionally, the quantitative model includes hired labor as a production input in the traditional and modern sectors. It also adds additional parameters in the Leontief production functions to allow them to better match the data and specifies the distribution of entrepreneur productivity. We describe the main features of the quantitative model below. We relegate the definition of an equilibrium to Appendix B.

\subsection{Grid Electricity Production}

We design a simple model of grid electricity production that captures the key features of electricity markets in developing countries discussed in Section 2, specifically the low electricity prices and frequent outages. We abstract from other aspects of electricity production, such as the degree of market power, different sources of electricity, and distinctions between generation, transmission, and distribution. These are important issues for some questions, but are 
not first order for our analysis.

There are measure one of electricity producers. Each electricity producer produces electricity from land, $b_{t}$, and grid capital, $k_{t}^{G}$, according to the production function:

$$
e_{t}^{G}=A^{G}\left(k_{t}^{G}\right)^{\psi} b_{t}^{1-\psi}
$$

Parameter $\psi$ denotes capital's share in grid-electricity production. The supply of land useful for electricity (e.g., hydro dam sites) is fixed and owned by the government. The electricity producers pay a licensing fee, $Q_{t}$, for each unit of land.

The electricity producer chooses grid capital, $k_{t}^{G}$, and land, $b_{t}$, to maximize profits, taking as given the grid electricity price, the licensing fee, and the rental rate for grid capital. Profits for each grid-electricity producer are:

$$
\pi_{t}^{G}=P^{G} A^{G}\left(k_{t}^{G}\right)^{\psi} x^{1-\psi}-R_{t} k_{t}^{G}-Q_{t} b_{t} .
$$

We assume that in equilibrium, the government sets the licensing fee, $Q_{t}$, so that the fixed supply of land is used at full capacity and all electricity producers earn zero profits (though this assumption is not central to our results). We normalize the supply of land to unity. The electricity producer's demand for grid capital and supply of grid electricity equal:

$$
k_{t}^{G}=\left(\frac{\psi P^{G} A^{G}}{R_{t}}\right)^{\frac{1}{1-\psi}} \text { and } e_{t}^{G}=\left(A^{G}\right)^{\frac{1}{1-\psi}}\left(\frac{\psi P^{G}}{R_{t}}\right)^{\frac{\psi}{1-\psi}} .
$$

Note that the key implication of equation (22) is that electricity producers respond to an increase in $P^{G}$ by raising their supply of electricity. The aggregate demand for grid capital and the aggregate supply of grid electricity equal the respective sums of capital demand and supply by each identical electricity producer: $K_{t}^{G} \equiv \int_{0}^{1} k_{t}^{G}=k_{t}^{G}$ and $E_{t}^{G} \equiv \int_{0}^{1} e_{t}^{G}=e_{t}^{G}$.

In line with the evidence discussed in Section 2, the government sets the grid-electricity price, $P^{G}$, at a value below that which would clear the grid-electricity market. Therefore, the price, $P^{G}$, does not clear the electricity market as it would in a standard competitive model. Instead, we assume that the probability that the power is on, $v_{t}$, adjusts endogenously to ensure that the total supply of grid electricity equals the total rationed demand for grid electricity. In particular, $v_{t}$ solves:

$$
E_{t}^{G}=v_{t} \int_{z_{t}^{\star}}^{\infty}(1-\gamma) e_{t}^{G}(0, z)+\gamma e_{t}^{G}(1, z) d G(z) .
$$


If the government raises the grid-electricity price, then equation (22) implies that electricity producers increase production, raising the supply of grid electricity. Holding demand constant, the increase in electricity supply raises the probability of grid power, $v_{t}$, that solves equation (23). On the demand side, the increase in the price of grid electricity reduces grid-electricity demand, while the increase in the probability of grid power operates though the firm-expansion and firm-entry channels to increase grid-electricity demand. In general equilibrium, the probability of grid power that solves equation (23) for each grid-electricity price depends on both the supply- and demand-side factors.

\subsection{Labor, Self-Generation, and Managerial Productivity}

The household is endowed with one unit of labor which she supplies inelastically to the labor market. She earns labor income $W_{t}$ in each period $t$. Both traditional and modern firms use labor, in addition to capital, in the production process. The traditional and modern production functions for a firm with productivity $z$ are:

$$
y_{t}^{T}=A^{T} z^{1-\eta}\left[\left(k_{t}^{T}\right)^{\alpha}\left(n_{t}^{T}\right)^{1-\alpha}\right]^{\eta} \quad \text { and } \quad y_{i t}^{M}=A^{M} z^{1-\eta}\left[\min \left(\left(k_{t}^{M}\right)^{\alpha}\left(n_{t}^{M}\right)^{1-\alpha}, \mu e_{i t}\right)\right]^{\eta} .
$$

Parameter $\alpha$ denotes capital's share in the capital-labor composite and parameter $\mu$ controls how much electricity is required to operate the capital-labor composite. Parameter $A^{T}$ denotes the TFP of the traditional sector. We define parameter $\phi>1$ to be the TFP boost from the modern production technology: $A^{M} \equiv \phi A^{T}$.

The production function for self-generated electricity is:

$$
e_{i t}^{S}=A^{S} \min \left[k_{t}^{S}, \chi f_{i t}\right]
$$

where parameter $A^{S}$ is TFP in the production of self-generated electricity and parameter $\chi$ controls how much fuel is required to operate the self-generation capital.

Each entrepreneur draws her level of managerial productivity, $z$, from the Pareto distribution:

$$
G(z)=1-\left(\frac{1}{z}\right)^{\lambda} \quad \text { where } \quad \lambda>1 \text { and } z \in[1, \infty]
$$

The equilibrium is defined as in Section 3, but now the probability of grid power, $v_{t}$, adjusts to clear the grid-electricity market and the wage, $W_{t}$, adjusts to clear the labor market. The formal definition of the equilibrium is in Appendix B. 


\subsection{Calibration}

We calibrate the model to provide quantitative estimates of the effects of power outages on output per worker and the contribution of the different general equilibrium channels. We focus on five major Sub-Saharan African economies: Ethiopia, Ghana, Nigeria, Tanzania, and Uganda. We first compute a baseline calibration using data from the Nigerian economy. We then recalibrate TFP and the key electricity-related parameters to match targets specific to each country in our study. The time period in the model is one year. We report all monetary values in year 2014 US dollars. We relegate the description of the data sources to Appendix B.2.

\subsubsection{Baseline Calibration: Nigerian Economy}

The calibration has two steps. First, we choose some parameters directly from the data and existing literature. Given these directly calibrated parameters, we choose a second set of parameters such that moments in the model match their empirical targets. Table 1 reports the values of the directly calibrated parameters.

We set the span-of-control parameter, $\eta$, equal to 0.85, as in Midrigan and Xu (2014). We use one third for capital's share in the capital-labor composite, $\alpha=0.33$. We set the depreciation rate, the CRRA coefficient and the discount rate equal to standard values of 0.06, 2 and 0.96, respectively. Parameter $\gamma$ equals the fraction of modern entrepreneurs that have access to generators. Viewing the World Enterprise Surveys as a survey of modern firms, parameter $\gamma$ corresponds to the fraction of firms that report access to generators (Figure 2), adjusted for the fact that not all firms in the World Enterprise Surveys experience outages (Figure 1). In Nigeria, 77.6 percent of firms experience outages and 70.7 percent of firms have access to generators. Thus, $\gamma$ equals the fraction of firms that experience outages that have access to generators, $\gamma=70.7 / 77.6=0.91$.

We are not aware of any direct empirical estimates of the price elasticity grid electricity, which would help pin down the value of $\psi$. Instead, we choose $\psi=0.7$ to reflect the relatively high capital share in electricity in the data. Section 5.2 reports the sensitivity of the main results to alternative values of this parameter. 
Table 1: Parameter Values: Direct Calibration

\begin{tabular}{lc}
\hline \hline Parameter & Value \\
\hline Span of control: $\eta$ & 0.85 \\
Capital share: $\alpha$ & 0.33 \\
Traditional productivity: $A^{T}$ & 1 \\
Modern productivity boost: $\phi$ & 1.43 \\
Fraction of modern entrepreneurs with generator access: $\gamma$ & 0.91 \\
Depreciation rate: $\delta$ & 0.06 \\
Grid electricity productivity: $A^{G}$ & 1 \\
Grid capital share: $\psi$ & 0.7 \\
CRRA coefficient: $\sigma$ & 2 \\
Discount rate: $\beta$ & 0.96 \\
\hline
\end{tabular}

Note: This table reports the baseline parameter values that we take from existing estimates.

We normalize grid-productivity, $A^{G}$, and traditional productivity, $A^{T}$, both to unity. Modern productivity parameter, $\phi$, determines the productivity boost an entrepreneur receives by switching to the modern production technology. Using data from six lower income economies, Lagakos (2016) finds that the productivity of the large modern segment of the retail sector is 1.43 times larger than the productivity of the smaller traditional segment. Based on this evidence, we set $\phi=1.43$. Section 5.2 explores the sensitivity of the main results to alternative values of $\phi$, and shows that the results are not as sensitive to this parameter as one might think.

We jointly calibrate the remaining parameters, $\left\{A^{S}, \chi, P^{G}, \lambda, \mu, \Omega\right\}$ so that moments in the model match their empirical targets. Table 2 reports the resulting parameter values. Table 3 reports the values of the moments we target in the model and in the data. We discuss each parameter and its primary target in turn.

The grid-electricity price, $P^{G}$, largely determines the level of grid capital, $K^{G}$, which in turn controls the supply of grid electricity. All else constant, the supply of grid electricity governs how much electricity firms can purchase from the grid and how much they must self-produce from generators. The World Enterprise Survey reports that Nigerian firms self-generate 58.8 percent of their total electricity consumption. We choose the regulated level of the grid-electricity price, $P^{G}$, to match this target.

The ratio of the average cost of self-generated electricity (green columns of Figure 3) to the average cost of grid electricity (blue columns of Figure 3) pins down self-generation productivity, $A^{S}$. For grid electricity, the firm's average cost equals the marginal cost, $P^{G}$. However, for self-generated electricity, the average cost differs from the marginal cost because the firm 
Table 2: Parameter Values: Method of Moments

\begin{tabular}{lc}
\hline \hline Parameter & Value \\
\hline Leontief parameter in final good production: $\mu$ & 1.59 \\
Leontief parameter in self-generated electricity production: $\chi$ & 2.14 \\
Self-generation productivity: $A^{S}$ & 1.30 \\
Grid-electricity price: $p^{G}$ & 0.08 \\
Entry cost: $\Omega$ & 0.32 \\
Pareto tail: $\lambda$ & 3.97 \\
\hline
\end{tabular}

Note: This table reports the baseline parameter values that we choose to match the empirical targets in Table 3.

must incur the fixed cost of renting the generator. To calculate the average cost of self-generated electricity, we add the variable cost calculated above to estimates of the capital and maintenance costs of a typical diesel generator (see Appendix B.2). The average cost of self-generated electricity equals 34 cents per kWh, 5.51 times larger than the average cost of grid electricity. Parameters $\Omega$ and $\lambda$ affect the number and size of modern firms. Using data from the Nigerian Survey of Micro, Small, and Medium Enterprises, we find that the modern sector employs 63 percent of workers and includes 30 percent of firms. We choose $\Omega$ and $\lambda$ to match these two targets.

Finally, the Leontief parameter in final goods production, $\mu$, determines electricity's share of modern production. Allcott et al. (2016) estimate that electricity share equals 7.4 percent of value added among Indian manufacturing firms. ${ }^{6}$ Since, electricity expenditures include expenditures on both grid and self-generated electricity, the probability of grid power could affect the electricity share. Furthermore, the probability of grid power in the Nigerian economy likely differs from Allcott et al. (2016)'s reported probability of 0.93 for Indian manufacturing firms. To align our model as closely as possible with the empirical target, we choose $\mu$ so that modern electricity share equals 7.4 percent in a counterfactual steady state in which the probability of grid power in Nigeria equals 0.93 . Table 3 reports the values of the moments in the model and the data. The model matches the targeted moments out to four decimal places.

\footnotetext{
${ }^{6}$ Similarly, Fisher-Vanden et al. (2015) find that the electricity share of value added equals 6 percent among Chinese manufacturing firms.
} 
Table 3: Model Fit

\begin{tabular}{lcc}
\hline \hline Moment & Model & Target \\
\hline (variable cost of self-generation)/(grid-electricity price) & 4.33 & 4.33 \\
(average cost of self-generation)/(grid-electricity price) & 5.51 & 5.51 \\
Fraction of self-generated electricity & 0.59 & 0.59 \\
Modern electricity share & 0.07 & 0.07 \\
Fraction of modern labor & 0.63 & 0.63 \\
Fraction of modern entrepreneurs & 0.30 & 0.30 \\
\hline
\end{tabular}

Note: This table reports the empirical and model values of the moments used to calibrate the parameters in Table 2 for the baseline economy. We compute the modern electricity share in the model in a counterfactual steady state in which the probability of grid power equals 0.93 . All the parameters in Table 2 are jointly determined by all of the moments. The model matches the targets out to four decimal places.

\subsubsection{Country-Specific Calibration}

Table 4: Country Specific Parameters

\begin{tabular}{lccccc}
\hline \hline Country & $\begin{array}{c}\text { Price of grid } \\
\text { electricity: } P^{G}\end{array}$ & $\begin{array}{c}\text { Self-gen } \\
\text { Leontief: } \chi\end{array}$ & $\begin{array}{c}\text { Self-gen } \\
\text { TFP: } A^{S}\end{array}$ & $\begin{array}{c}\text { Trad. TFP: } \\
A^{T}\end{array}$ & $\begin{array}{c}\text { Generator access } \\
\text { probability: } \gamma\end{array}$ \\
\hline Ethiopia & 0.03 & 2.03 & 2.86 & 0.41 & 0.61 \\
Ghana & 0.10 & 1.75 & 1.94 & 0.75 & 0.58 \\
Nigeria & 0.08 & 2.14 & 1.30 & 1.00 & 0.91 \\
Tanzania & 0.07 & 1.51 & 3.44 & 0.53 & 0.50 \\
Uganda & 0.08 & 1.63 & 3.56 & 0.45 & 0.64 \\
\hline
\end{tabular}

Note: This table reports the values of the country-specific parameters in the model. We measure the fraction of modern firms with access to generators, $\gamma$, directly from the data. We calibrate the remaining parameters to match the empirical targets in Table 5.

We re-calibrate the four electricity-related parameters, $\left\{A^{S}, \chi, \gamma, P^{G}\right\}$ and traditional productivity, $A^{T}$, for each remaining country in our study. All other parameter values are constant across countries and equal to their values in the baseline calibration (Tables 1 and 2). Table 4 reports the values of the country-specific parameters.

For each country, we measure the fraction of modern firms that have access to generators, $\gamma$, directly from the World Enterprise Survey data reported in Figure 2, adjusting for the frequencies of outages reported in Figure 1. We calibrate the remaining four parameters so that four moments in the model directly match their corresponding empirical targets. In particular, we choose $\chi$ and $A^{S}$ for each country to match the ratios of the average and marginal cost of selfgenerated electricity relative to grid electricity (using the same data as in Figure 3). We choose the regulated grid-electricity price, $P^{G}$, to match the country-specific fractions of self-generated 
electricity reported in the Word Enterprise Surveys. We determine the country-specific values of $A^{T}$ to match the ratio of output per worker in the specific country relative to its value in Nigeria. Table 5 reports the values of these country-specific targets. The calibrated model in each country matches the corresponding targets out to four decimal places.

Table 5: Country-Specific Targets

\begin{tabular}{lcccc}
\hline \hline Country & (AC self)/(AC grid) & (MC self)/(MC grid) & $E^{s} /\left(E^{s}+E^{g}\right)$ & $Y / Y_{N G A}$ \\
\hline Ethiopia & 8.61 & 6.84 & 0.49 & 0.25 \\
Ghana & 3.66 & 3.00 & 0.22 & 0.67 \\
Nigeria & 5.51 & 4.33 & 0.59 & 1.00 \\
Tanzania & 3.22 & 2.70 & 0.25 & 0.38 \\
Uganda & 2.48 & 2.05 & 0.18 & 0.33 \\
\hline
\end{tabular}

Note: This table reports the empirical values of the country-specific targets for each of the five countries in our study. The targets are: (1) the average cost of self-generated electricity relative to grid electricity, (2) the marginal cost of self-generated electricity relative to grid electricity, (3) self-generated electricity relative to total electricity and (4) output per worker in the specific country relative to output per worker in Nigeria.

\section{Quantitative Results}

In our main experiment, we simulate the effects of eliminating outages by letting the price of grid electricity adjust to clear markets. ${ }^{7}$ Introducing a market-clearing electricity price is a purely counterfactual exercise in the sense that no African country has implemented such a reform (Eberhard et al., 2011). Hence, our model provides the necessary laboratory to explore how increasing the electricity price to eliminate outages would affect output, consumption, and other macroeconomic aggregates.

\subsection{Long-Run General-Equilibrium Effects of Eliminating Power Outages}

To quantify the long-run general-equilibrium effect of eliminating outages in each country, we compare the country's initial calibrated steady state with a counterfactual "no-outages" steady state. In the no-outages steady state, we de-regulate the electricity market by allowing the price to adjust so that grid-electricity supply exactly equals demand. The resulting increase in the grid-electricity price eliminates outages by increasing the supply of grid capital and grid electricity (equation 22). The first column of Table 6 reports the percent increase in the gridelectricity price between the initial and no-outages steady states in each country. The second and third columns report the corresponding increases in grid-electricity capital and supply.

\footnotetext{
${ }^{7}$ Note that this experiment involves raising price as well as increasing the reliability of the grid. Raising the price alone has negative effects on firms in the model, since it raises production costs and reduces output. This is consistent with the empirical findings of Abeberese (2017), who documents that higher electricity prices for Indian manufacturing firms resulted in lower output and labor productivity growth.
} 
Table 6: Grid Electricity Price, Capital, and Supply

\begin{tabular}{lccc}
\hline \hline & \multicolumn{3}{c}{ Percent change from the initial steady state } \\
\cline { 2 - 4 } & Grid price: $P^{G}$ & Grid capital: $K^{G}$ & Grid electricity: $E^{G}$ \\
\hline Ethiopia & 338 & 13,614 & 3,033 \\
Ghana & 41 & 212 & 122 \\
Nigeria & 81 & 617 & 297 \\
Tanzania & 71 & 494 & 248 \\
Uganda & 36 & 179 & 105 \\
\hline
\end{tabular}

Note: Column (1) reports the percent increase in the grid-electricity price from its value in each country's initial steady state necessary to eliminate outages. Columns (2) and (3) report the corresponding percent increases in grid-electricity capital and supply.

Eliminating outages requires substantial increases in grid-electricity prices, capital, and supply across all five countries. Ghana, Nigeria, Tanzania and Uganda require between a 30 and 80 percent increase in the grid-electricity price, resulting in two- to seven-fold increases in grid capital. These are accompanied by large increases in grid-electricity supply. Ethiopia stands out with more than a quadrupling of the grid-electricity price required to clear the electricity market, generating over a 14-fold increase in the level of grid capital. Both the gridelectricity price and the level of grid capital in Ethiopia are extremely low in the initial steady state (see Appendix Table B.3). Consequently, the large proportional increases in Ethiopian grid-electricity prices, capital, and supply occur because the electricity sector is very distorted and, mechanically, because of the low initial steady-state values, from which the proportional increases are measured.

Figure 6 plots the long-run general-equilibrium effect of eliminating outages. Eliminating outages leads to large increases in output per worker in all countries, ranging from 16.8 percent in Uganda to 30.7 percent in Ethiopia. Ghana, Nigeria, and Tanzania are in the middle, with increases in output per worker equal to $24.9,28.4$, and 27.1 percent, respectively. Averaging across all five countries, eliminating outages increases output per worker in the long-run general equilibrium by approximately 25 percent.

To better understand the sources of productivity gains from eliminating outages, we decompose the total increase in output per worker into three components, corresponding to the three sections of each bar in Figure 6. The green section shows the short-run partial-equilibrium effect, which is the increase in output per worker that results when outages are eliminated expost, after entrepreneurs have already made their scale and entry decisions. Specifically, we hold firm size, the productivity cutoff, and all prices constant and compute output per worker if the probability of grid power equals one, instead of its value in the initial steady state. This 
Figure 6: Long-Run General-Equilibrium Effects of Eliminating Power Outages

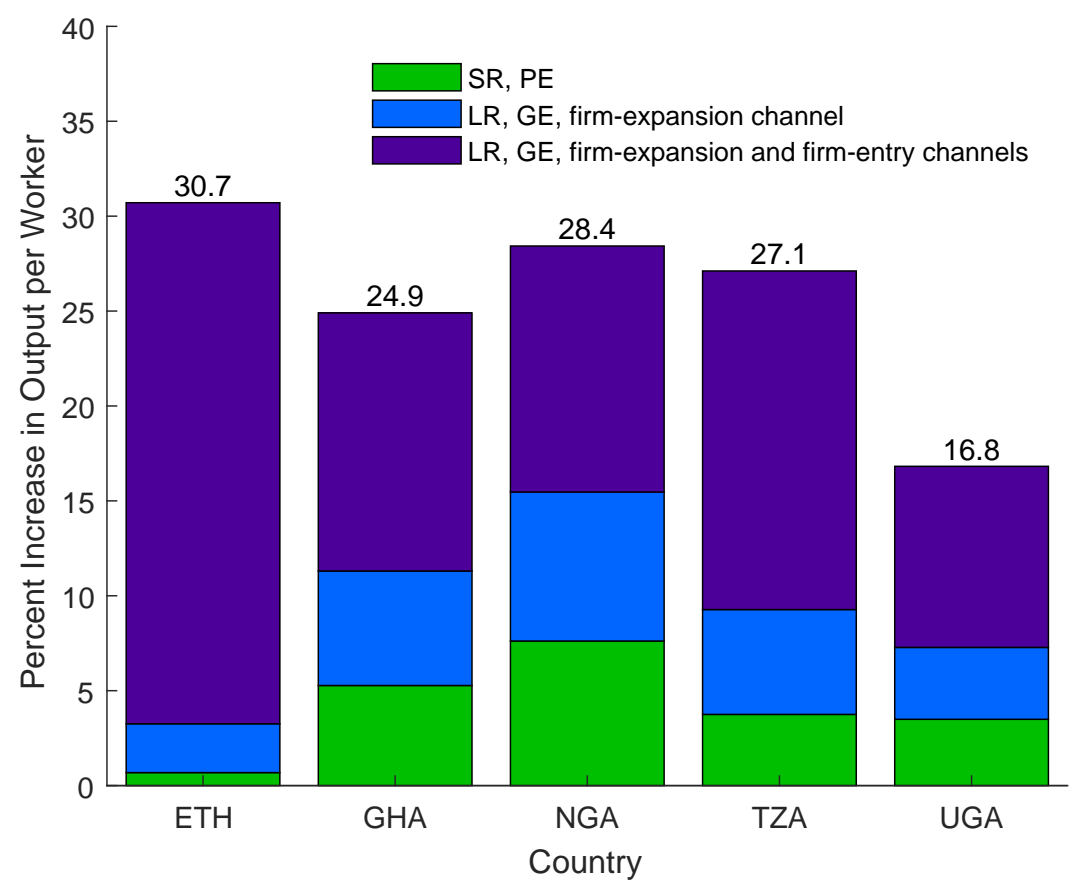

Note: The height of each bar equals the total steady-state increase in output per worker from eliminating power outages in each country. The green, blue and purple regions of each bar correspond to the relative contributions from the short-run partial-equilibrium effect, the firm-expansion channel and the firm-entry channel, respectively.

exercise is truly partial equilibrium in the sense that we do not require the markets for capital, labor, or electricity to clear.

Consistent with the microeconomic evidence (e.g., Allcott et al., 2016, and the other studies cited in the introduction), the short-run partial-equilibrium effects of eliminating outages are small, ranging from 0.7 percent in Ethiopia to 7.6 percent in Nigeria. Averaging across all five countries, eliminating outages in the short-run partial equilibrium only increases output per worker by approximately 4 percent. Comparing the short-run partial equilibrium effect with the long-run general-equilibrium effect (equal to the full height of each bar in Figure 6) reveals that the long-run general-equilibrium effects are around five times larger, on average. Hence, as Buera et al. (2012) also find in the microfinance context, the short-run partial equilibrium effect is an important component of the total macroeconomic impact, but it is far from the whole story.

The large long-run effects do not result from large (counterfactual) short-run partial-equilibrium effects, but instead from the additional increases in output per worker generated by the firmexpansion and firm-entry channels. The blue and purple sections of each bar represent the increase in output per worker from adding the firm-expansion and firm-entry channels, re- 
spectively. To isolate the effects of the firm-expansion channel (blue sections), we solve for a no-outages steady state in which the productivity cutoff, $z^{\star}$, is fixed at its value in the initial steady state. In this exercise, all markets clear, but entrepreneurs' sector decisions do not necessarily satisfy the entry condition in equation (9). The additional increases in output per worker from the firm-entry channel (purple sections) equal the difference between the nooutages steady state and the no-outages steady state with the productivity cutoff fixed at its value in the initial steady state.

As Figure 6 shows, both the firm-entry and the firm-expansion channels are large relative to the short-run partial-equilibrium effect. The firm-entry channel is somewhat larger than the firm-expansion channel (i.e., the purple sections of each bar are larger than the blue sections) because the ability of the firm-expansion channel to increase output per worker is constrained by the size of the modern sector in the initial steady state. While all existing modern firms scale up production, if there are very few modern firms, then this increase in scale will have only a small effect on output per worker. Indeed, Ethiopia has the smallest modern sector in the initial steady state (see Appendix Table B.3) and experiences the largest difference in the effects of the firm-expansion and firm-entry channels.

To quantify the broader macroeconomic consequences of eliminating outages in each country, Table 7 reports the percent change in a number of variables in the no-outages steady state relative to their values in the initial steady state. Eliminating outages leads to substantial increases in the size of the modern sector, measured either by the number of modern firms, $Q^{M}$, or by the number of modern workers, $N^{M}$ (first two rows of Table 7). Since the total numbers of firms and workers are fixed, the increases in the numbers modern firms and workers generate parallel decreases in the numbers of traditional firms and workers.

Eliminating outages leads to large increases in the equilibrium wage, ranging from 11 percent in Uganda to 26 percent in Nigeria (third row of Table 7). The reason for the increase in wages is that the number of modern firms increases and existing modern firms rent additional capital and purchase more electricity, all of which increase the marginal product of labor. The rental rate of capital is pinned down entirely by the household-Euler equation and is thus unchanged, as in the analytic version of the model in Section 3. Productive capital in the traditional and modern sectors moves in opposite directions (fourth and fifth rows of Table 7). The combined effects of the firm-expansion and firm-entry channels lead to substantial increases in productive capital in the modern sector. Capital in the traditional sector falls both because the firm-entry channel implies that there are fewer traditional firms and because the higher wages cause traditional firms to hire fewer workers, reducing their demand for capital.

The final three rows of Table 7 report the effects of eliminating outages on the aggregate capital 
stock, measured TFP, and consumption. Following the development accounting literature (Hall and Jones, 1999; Caselli, 2005) we define measured TFP as aggregate output, $Y$, divided by a Cobb-Douglas aggregate of measured capital and labor, $\tilde{K}^{\alpha} N^{1-\alpha}$, where $\alpha$ equals the calibrated value of capital share, 0.33 . To be conservative, we define measured capital, $\tilde{K}$, to equal the aggregate capital stock plus entry costs, which can be thought of as a type of capital.

Table 7: Effects of Eliminating Outages on Macro Aggregates

\begin{tabular}{lccccc}
\hline & \multicolumn{5}{c}{ Percent change from the initial steady state } \\
\cline { 2 - 6 } & Ethiopia & Ghana & Nigeria & Tanzania & Uganda \\
\hline Modern entrepreneurs: $Q^{M}$ & 3,513 & 158 & 129 & 326 & 120 \\
Modern labor: $N^{M}$ & 1,421 & 64 & 52 & 149 & 63 \\
Wage rate: $W$ & 17 & 21 & 26 & 18 & 11 \\
Modern productive capital: $K^{M}$ & 1,677 & 98 & 91 & 193 & 81 \\
Traditional capital: $K^{T}$ & -67 & -74 & -82 & -68 & -51 \\
Aggregate capital stock: $K$ & 46 & 28 & 31 & 36 & 22 \\
Measured TFP: $Y /\left(\tilde{K}^{\alpha} N^{1-\alpha}\right)$ & 14 & 14 & 17 & 14 & 9 \\
Consumption: $C$ & 18 & 17 & 21 & 17 & 11 \\
\hline
\end{tabular}

Note: This table reports the percent change in a number of variables in the no-outages steady state from their corresponding values in the initial steady state. Measured TFP equals aggregate output divided by a CobbDouglas aggregate of measured capital and labor, $\tilde{K}^{\alpha} N^{1-\alpha}$, where $\alpha$ equals 0.33 . Measured capital, $\tilde{K}$, equals the aggregate capital stock plus entry costs.

Eliminating outages leads to substantial increases in the aggregate capital stock, ranging from 31 percent in Nigeria to 46 percent in Ethiopia, implying that capital accumulation is an important driver of the gains in output per worker reported in Figure 6. However, the increases in output per worker do not result from capital accumulation alone. We also see large increases in measured TFP, ranging from 9 percent in Uganda to 17 percent in Nigeria. Eliminating outages increases measured TFP because it eliminates idle resources and because it shifts entrepreneurs to the more-productive modern sector. The higher steady-state capital stock and measured TFP generate substantial increases in consumption.

\subsection{Sensitivity}

To provide insights on the underlying mechanisms driving the quantitative results, we explore the sensitivity of the results for the Nigerian economy to the following parameter values and targets: (1) capital's share in grid electricity production, $\psi,(2)$ the productivity boost from becoming modern, $\phi$, (3) grid-electricity's share in modern production, and (4) the average and marginal costs of self-generated electricity. In each case, we re-calibrate all the parameters in the Nigerian economy to either match the new set of targets or to account for the change 
in the directly calibrated parameter value. The four panels of Table 8 report the effects of eliminating outages on output, consumption, and capital for each sensitivity exercise. The middle row in every panel corresponds to the baseline calibration.

Table 8: Sensitivity to Parameter Values and Targets

\begin{tabular}{lccc}
\hline & \multicolumn{3}{c}{ Percent change from the initial steady state } \\
\cline { 2 - 4 } & Output: $Y$ & Consumption: $C$ & Capital: $K$ \\
\hline Capital share in grid-electricity production: $\psi$ & & \\
\hline$\psi=0.6$ & 22 & 16 & 24 \\
$\psi=0.7$ & 28 & 21 & 31 \\
$\psi=0.8$ & 35 & 27 & 37 \\
\hline Modern productivity boost: $\phi$ & & & 29 \\
\hline$\phi=0.3$ & 26 & 20 & 31 \\
$\phi=0.43$ & 28 & 21 & 33 \\
$\phi=0.5$ & 31 & 22 & 24 \\
\hline Electricity share of modern output & & 15 & 31 \\
\hline Share $=0.05$ & 23 & 21 & 41 \\
Share $=0.074$ & 28 & 30 & 25 \\
Share $=0.1$ & 37 & & 31 \\
\hline Self-generation costs & & 14 & 40 \\
\hline 50 percent decrease in costs & 21 & 21 & \\
Baseline costs & 28 & 36 & \\
50 percent increase in costs & 41 & & \\
\hline
\end{tabular}

Note: This table reports the percent increase in aggregate output, consumption, and capital between the initial and no-outages steady states in the Nigerian economy for different perturbations of the parameters and targets. The four panels correspond to perturbations of the capital share in grid-electricity production, the modern productivity boost, the electricity share of modern output in the counterfactual steady state with $v=0.93$, and the self-generation costs. The middle row in every panel corresponds to the baseline calibration.

Higher values of the capital share in grid-electricity production, $\psi$, imply weaker diminishing returns in grid-electricity production. As a result, de-regulating the electricity market leads to a smaller increase in the grid-electricity price and a larger increase in the grid-electricity supply, magnifying the gains in output per worker. Higher values of the modern productivity boost, $\phi$, increase the gains in output per worker from the firm-entry channel, raising the total increase in output per worker. However, the impact of changes $\phi$ are smaller that one might expect because the model must match the same empirical targets in the initial steady state. For example, all else constant, higher values of $\phi$ make the modern sector more attractive, increasing the size and number of modern firms. Consequently, matching the empirical shares 
of modern labor and firms with a higher value of $\phi$ requires a larger entry cost, $\Omega$, and a larger Pareto distribution parameter, $\lambda$. The larger values of $\Omega$ and $\lambda$ partially offset the impact from the larger value of $\phi$ on the increase in output per worker from eliminating outages.

As one might expect, the effects of eliminating outages depend on electricity's share of modern output, which determines the relative importance of electricity as a production input, and on the costs of self-generation, which determines the cost of electricity during an outage (last two panels of Table 8). At the extreme lower bound, if electricity did not enter modern production at all (so that its share equaled zero) or if the cost of self-generation equaled the cost grid electricity, then eliminating outages would have no effect on output per worker. Increasing either of these variables from this lower bound necessarily increases the long-run general-equilibrium effects of eliminating outages. Importantly, the values used in the baseline calibration for electricity's share of modern output and the self-generation costs are disciplined by direct empirical evidence from developing economies. Thus, while the actual values could always differ, in practice, we expect that they will be relatively close to the baseline calibration.

Finally, our main results assume that fraction $\gamma$ of modern entrepreneurs have access to generators and fraction $1-\gamma$ do not, where the value of $\gamma$ is disciplined by the evidence on generator ownership from the World Enterprise Surveys. Importantly, when $v<v^{\star}$ (as it is in the initial steady state for all five countries) firms with generator access endogenously choose a larger scale than firms without generator access. Hence, the model is consistent with the empirical evidence that firms with generators are larger than those without (see e.g. Foster and Steinbuks, 2008; Alby et al., 2013). However, it is also possible that generator access is correlated with unobservable firm productivity, $z$. Since we have no direct evidence on this correlation, we instead bound our main results in Figure 6 from below by re-calibrating and re-solving our model assuming that all modern firms have generator access. We find that while the magnitudes are smaller than in our main results, the increases in output per worker from eliminating outages are still substantial, ranging from 8.2 percent in Uganda to 24.0 percent in Ethiopia (see Appendix Figure B.1).

\subsection{Insights on Weak Links and Aggregate Productivity}

One insight from the previous literature is that aggregate productivity may not be as affected by weak link sectors as one might think, since a competitive economy can compensate by allocating more inputs to those sectors (Jones, 2011). The logic is that if output from a weaklink sector is sufficiently scarce, then its price will rise to attract more inputs, thus raising output in the weak-link sector. In our context, with electricity rationed through power outages, these forces do not operate in the same way. The electricity price is regulated to be artificially low, 
Figure 7: Competitive Economy versus Outages Economy
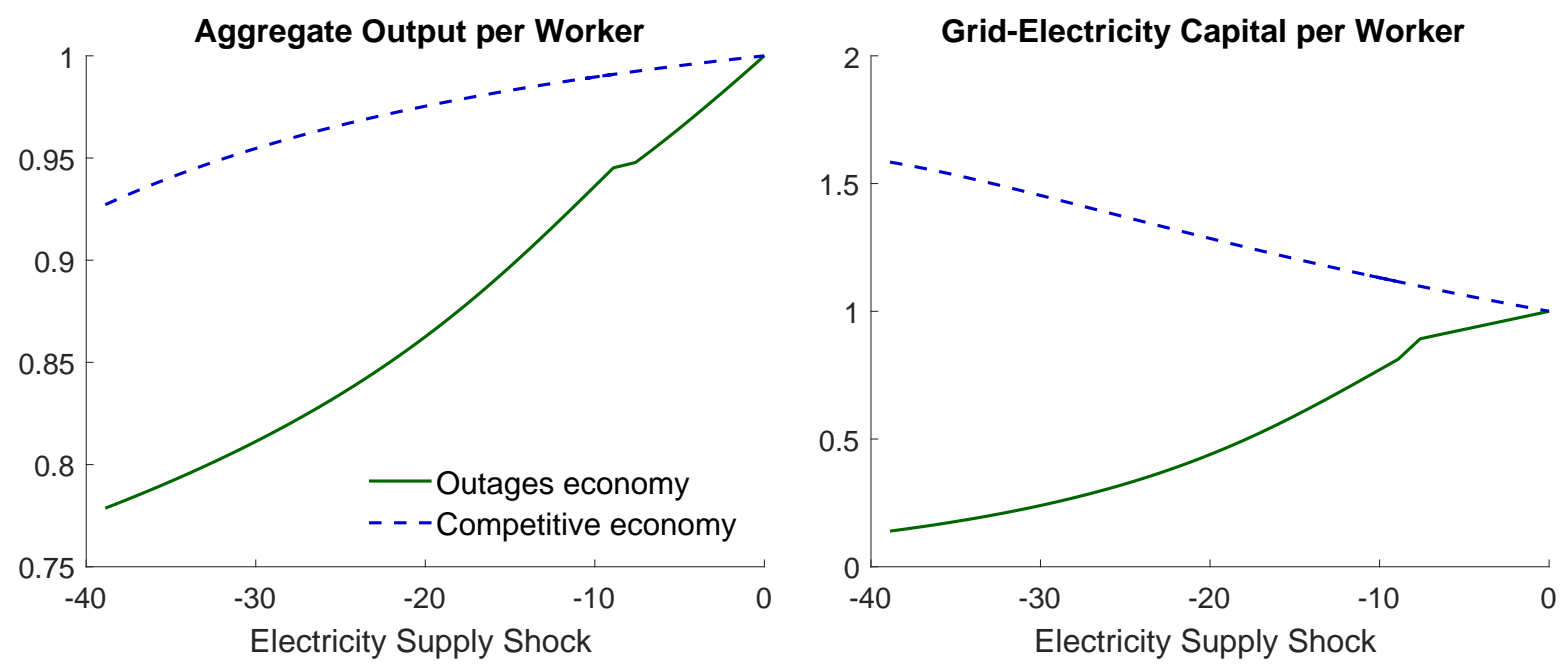

Note: This figure plots the responses of output per worker and grid-electricity capital per worker in Nigeria to an electricity supply shock in our outages economy (solid green line) and in a competitive economy (dashed blue line). The right-most point on the solid green line in both panels corresponds to the counterfactual nooutages steady state for Nigeria and the left-most point corresponds to the initial steady state. Moving from right to left along the outages-economy (solid green) line, we reduce the price of grid-electricity so that total electricity supply (grid plus self-generated) in steady state decreases by the amount on the x-axis. Moving from right to left along the dashed blue line, we reduce productivity in grid-electricity production, $A^{G}$, by the percentage on the $\mathrm{x}$-axis.

which prevents resources from reallocating to the electricity sector and, as a result, the weak link in the electricity sector can more severely constrain aggregate output.

To illustrate the how the effects of power outages differ from low productivity in the electricity sector, Figure 7 plots the responses of output per worker and grid-electricity capital per worker to an electricity supply shock in our outages economy (solid green line) and in a competitive economy (dashed blue line) in which the grid-electricity price adjusts to clear the market. The right-most point in both panels corresponds to the counterfactual no-outages steady state for Nigeria. Moving from right to left along the outages-economy (solid green) line, we reduce the price of grid-electricity so that total electricity supply (grid plus self-generated) in steady state decreases by the amount on the x-axis. Hence, as one moves from right to left, the probability of grid power falls and outages become more frequent. The left-most point corresponds to the initial steady state in the Nigerian economy. ${ }^{8}$

Moving from right to left along the dashed blue line, we conduct a similar exercise for the com-

\footnotetext{
${ }^{8}$ In a small region right around the productivity cutoff, $v^{\star}$, there are two different steady states that generate the same amount of grid-electricity supply, one in which $v<v^{\star}$ and relatively more electricity comes from generators and one in which $v>v^{\star}$ and relatively more electricity comes from the grid. As a convention, we plot only the steady state with $v<v^{\star}$ when there are two steady states. Plotting instead only the steady state with $v>v^{\star}$ when there are two steady states does not meaningfully change the graph.
} 
petitive economy by reducing productivity in grid-electricity production, $A^{G}$, by the percentage on the x-axis. This exercise results in higher grid-electricity prices, but no outages, because the price endogenously adjusts to clear the grid-electricity market.

The electricity-supply shocks lead to larger decreases in output per worker in the outages economy than in the competitive economy; moving from right to left in the left panel of Figure 7, the solid green line falls farther and farther below the dashed blue line. Indeed, going all the way to the initial steady state (left-most point on the x-axis), output per worker falls by almost 25 percent in the outages economy but by less than 10 percent in the competitive economy. The reason for the difference is that in the competitive economy, the endogenous increase in the grid-electricity price attracts more capital to the grid-electricity sector, which substitutes for the low productivity, thus alleviating the constraints on aggregate output. In contrast, in the outages economy, the artificially low grid-electricity price causes capital to leave the gridelectricity sector, reducing supply and creating outages. The right panel of Figure 7 illustrates these opposite responses; moving from right to left, grid-capital per worker increases in the competitive economy (dashed blue line) and decreases in the outages economy (solid green line).

In sum, the distortions in the electricity sector, caused by artificially depressed prices, fundamentally differ from those caused by low sector productivity in a competitive economy. Competitive forces can alleviate the consequences of low productivity by raising the price to attract more resources to the low-productivity sector. But competitive forces cannot alleviate the consequences of depressed prices since, by design, the price cannot adjust to reflect the true scarcity of the input. Instead, the depressed prices discourage investment in electricity production, resulting in shortages. Thus, as long as electricity prices are artificially low, the electricity sector is likely to remain a weak link.

\section{Supporting Evidence}

Our theory predicts that eliminating power outages would cause existing firms to expand their operations and new firms to operate better technologies that require electricity. In this section, we use two approaches to validate these two channels. First, we cite the existing empirical evidence on the effects of outages on firm expansion and firm entry. Second, we provide new survey evidence from firms in Ghana and Nigeria about the expected effects of permanently eliminating outages on their businesses and industries. 


\subsection{Existing Evidence}

It is challenging to empirically estimate the long-run general-equilibrium effect of eliminating outages because, to our knowledge, no developing country in the modern era has been able to eliminate outages for any significant period of time. Two studies that estimate related channels are by Reinikka and Svensson (2002) and Kassem (2020). Using cross-sectional data from 171 Ugandan firms, Reinikka and Svensson (2002) find that among firms without generators, those that experience more outages undertake less investment. They find no statistically significant effect for firms with generators. While the firm-expansion channel in our model implies that power outages reduce investment for modern firms with and without generators, the impact is considerably larger for firms without generators, consistent with Reinikka and Svensson (2002)'s findings.

Kassem (2020) exploits regional variation in the roll out of the Indonesian electric power grid to estimate the effects of grid connections on the size and structure of the manufacturing sector. She finds that access to the national electric grid increases both the number and size of manufacturing firms. In the context of our model, gaining access to the electric grid corresponds to an increase in the probability of grid power from zero to some positive number. Hence, we view her results as supporting the model's theoretical predictions that increases in the probability of grid power will cause existing firms to expand and new firms to enter.

\subsection{New Survey Results From African Firms}

To supplement the existing empirical evidence, we survey firms about their expectations for what would happen if electricity outages were permanently eliminated. We do so using new surveys of business owners in Ghana and Nigeria. The main advantage of this approach is that we can directly ask firms in two of the countries we include in our analysis about the specific channels in our model.

\subsubsection{Survey Data}

Our surveys cover a sample of firm owners in Ghana and Nigeria, and were conducted from June to August 2019. We implemented the surveys with Google Surveys, a platform that allows users to survey a random sample of internet news readers. The readers are incentivized to take the survey by being offered free access to the remainder of their news article after completing the survey. Readers are also given the option to opt out of any survey. We identified business owners with an initial screening question about whether the respondent currently owned and operated a business. We then asked the business owners between three and six additional questions, depending on the survey. We ran a total of 34 surveys covering 3,425 firms, of 
which 1,913 were from Ghana and 1,512 were from Nigeria. The overall dropout rate was low after the initial screening question, at slightly less than 14 percent, and we kept only those responding to all questions, which was most of the respondents.

Not surprisingly, the business owners in our surveys were disproportionately educated and living in urban areas. In Ghana, for example, 89 percent of respondents had completed secondary school or more and 93 percent came from the largest two cities of Accra and Kumasi. One would not want to use these surveys to learn about rural farmers or entrepreneurs in the traditional sector in urban centers. Yet they may not be a bad approximation to those operating in the modern sector in our model, since modern-sector entrepreneurs in the model are those with the highest productivity levels.

Importantly, firms in our surveys were representative in that they reported regularly experiencing power outages and use of generators to self-produce power. When asked about the frequency of power outages in the last year, the most common answer in both countries was 10 or more times, with 46 percent of Nigerians and 23 of Ghanians selecting this answer. Just 23 percent of Ghanian firms and of 11 percent of Nigerian firms reported not having any outages in the last year. On average, 55 percent of firms in Ghana and 85 percent in Nigeria reported that they owned or had access to a generator. These statistics line up well with those from the World Bank Enterprise Surveys presented in Section 2. Firms in our survey are also consistent with World Bank Enterprise Surveys in their skewness toward smaller firm sizes relative to richer countries (see Appendix C), and their industry composition being primarily services and only partly manufacturing and agriculture.

\subsubsection{Expected Effects of Eliminating Outages}

To understand how eliminating power outages would affect firms in the developing world, we asked a series of hypothetical questions to the Ghanaian and Nigerian firm owners about their expectations for what would happen if outages were eliminated. We focused on four main outcomes: profits, expansion through investment, expansion through hiring, and entry of new firms in the same industry. For the first three questions we ask about the effects of eliminating power outages "for your firm" and for the last we specify that power outages would be eliminated in their country. For all questions we asked how likely the firms felt each outcome would be if power outages were eliminated, with the options being "very unlikely," "unlikely," "neutral," "likely," "very likely" and "I don't know."

One potential limitation of any survey - and online surveys in particular - is that respondents may provide uninformative answers or answers based on what they expect the surveyors would like to hear. In order to measure how common this is among the respondents in our setting, we 
Figure 8: Effects of Eliminating Power Outages from the Firms' Perspective

(a) Ghana

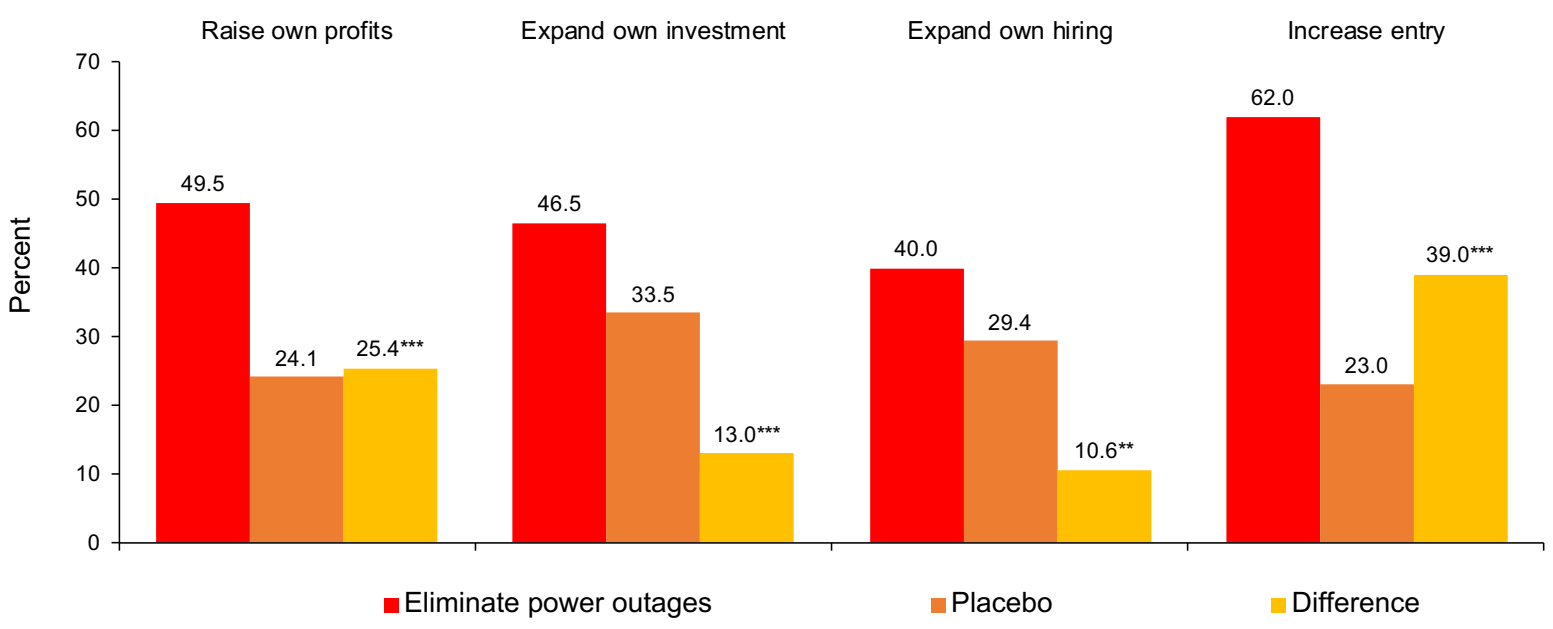

(b) Nigeria

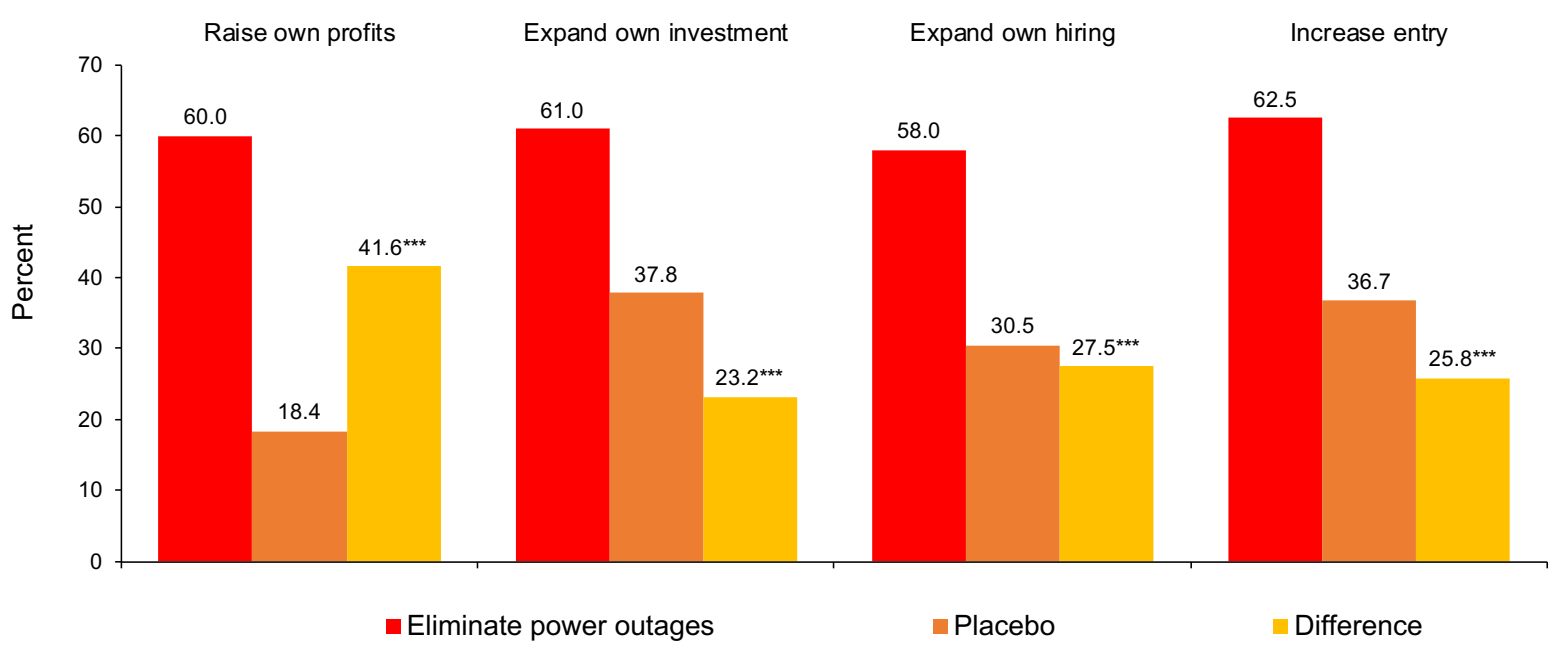

Note: This figure plots the percent of firms answering that each effect is "likely" or "very likely" if power outages were permanently eliminated (red bars). The other choices are "very unlikely," "unlikely," "neutral" and "don't know." The frame of references is a placebo scenario in when the national airports would convert to solar power (orange bars). The difference is plotted (yellow bars) along with $* * *, * *$ or * to represent the $p$ value of the test of the null hypothesis that the difference between eliminating power outages and the placebo is zero being less than 1 percent, 5 percent and 10 percent.

ran a series of surveys that asked firms about the expected effects of a placebo "treatment" in which the national airports in Ghana or Nigeria convert to solar power. The advantage of this placebo treatment is that it is a policy issue related to electricity, as in our main questions about eliminating power outages, but it would be quite unlikely to affect the vast majority of firms. In all of the surveys about the placebo treatment, we asked about exactly the same outcomes and used the exact same response options as the main surveys on power outages, so as to make 
apples-to-apples comparisons.

Figure 8 plots the percentage of firms responding that each outcome would be "likely" or "very likely" if power outages were permanently eliminated. As a frame of reference we plot the percentage responding that each outcome would be "likely" or "very likely" under the placebo treatment. We also plot the simple difference between the two percentages, and summarize the $p$-values of a test of the difference in the two proportions with three, two or one stars to represent significance at the 1-, 5- and 10-percent level. Panels (a) and (b) present the results from Ghana and Nigeria, respectively.

As Figure 8 shows, the majority of firms owners expect that eliminating power outages for their firm would raise profits and lead them to expand by making new investments and increasing hiring. Relative to the placebo treatment, 25.4 percent more Ghanaian firms and 41.6 percent more Nigerian firms expect that eliminating power outages would be "likely" or "very likely" to raise their profits. Firms in both countries were also significantly more likely to report that eliminating power outages would lead them to expand through increased investment or by increasing their hiring. These differences are all statistically significant at the 5-percent level or lower. These results provide support for the model's predictions that permanently eliminating power outages would lead firms to expand.

The last columns of Figure 8 report the firms' expectations for how eliminating power outages would affect the entry of new firms into their industries. Relative to the placebo, 39 percent more Ghanaian firms report that eliminating power outages would be likely or very likely to increase entry. In Nigeria, it is 25.8 percent more firms. Both are statistically significant differences, suggesting that firms do expect that eliminating outages would increase entry, as our model predicts.

\section{Conclusion}

Unreliable electricity is widely thought by policymakers to be a major constraint on firm productivity in the developing world. Yet most empirical studies of how power outages affect firm performance conclude that eliminating outages would lead to very modest productivity increases. Our paper is the first to model and quantify the long-run general-equilibrium effects of eliminating power outages. In contrast to the previous literature, we find that eliminating outages generates large increases in aggregate output per worker across the five Sub-Saharan African countries in our study, on the order of 25 percent. Through the lens of development accounting, eliminating outages works through increases in aggregate capital per worker, as firms expand, and through increases in TFP, as fewer productive resources are idled and more 
firms operate with more-productive, electricity-using technologies.

Our model abstracts from several mechanisms through which electricity could increase output per capita, implying that our quantitative results may be a lower bound. First, temporary outages may permanently damage production. The production of semiconductors represents one extreme, in which a split-second interruption in the power supply reportedly damaged chips that take weeks to produce (Clark and Osawa, 2010). These potential disruptions imply that frequent power outages could deter some industries, such as semiconductors, from locating in a country altogether. On the household side, electricity may also raise labor supply through the adoption of time-saving home appliances (Dinkelman, 2011; Gertler, Shelef, Wolfram, and Fuchs, 2016) or encourage human capital accumulation (Vidart, 2020). Future work should explore other channels through which electricity raises income levels in the long run.

\section{References}

Abeberese, A. B. (2017): "Electricity Cost and Firm Performance: Evidence from India," Review of Economics and Statistics, 99, 839-852.

Abeberese, A. B., C. G. AckAh, And P. O. Asuming (2019): "Productivity Losses and Firm Responses to Electricity Shortages: Evidence from Ghana," World Bank Economic Review.

Acemoglu, D., P. Aghion, L. Bursztyn, And D. Hémous (2012): "The Environment and Directed Technical Change," American Economic Review, 102, 131-166.

AKCigit, U., H. AlP, AND M. Peters (Forthcoming): "Lack of Selection and Limits to Delegation: Firm Dynamics in Developing Countries," American Economic Review.

Alby, P., J.-J. DethieR, AND S. Straub (2013): "Firms Operating under Electricity Constraints in Developing Countries," World Bank Economic Review, 27, 109-132.

Allcott, H., A. Collard-WeXler, And S. D. O'Connell (2016): “How Do Electricity Shortages Affect Productivity? Evidence from India," American Economic Review, 106, 587-624.

AtAlay, E. (2017): "How Important Are Sectoral Shocks?" American Economic Journal: Macroeconomics, 9, 254-280.

AtKeson, A. And P. J. Kehoe (1999): "Models of Energy Use: Putty-Putty versus Putty-Clay," American Economic Review, 89, 1028-1043.

BAQAEE, D. R. AND E. FARHI (2019): “The Macroeconomic Impact of Microeconomic Shocks: Beyond Hulten's Theorem," Econometrica, 87, 1155-1203.

(2020): "Productivity and Misallocation in General Equilibrium," Quarterly Journal of Economics, 131, 105-163. 
BARRAge, L. (2019): "Optimal Dynamic Carbon Taxes in a Climate-Economy Model with Distortionary Fiscal Policy," Review of Economic Studies, 87, 1-39.

BARTElme, D. AND Y. Gorodnichenko (2015): "Linkages and Economic Development," NBER Working Paper No. 21251.

Boehm, J. AND E. OBerfield (2018): "Misallocation in the Market for Inputs: Enforcement and the Organization of Production," Unpublished Working Paper, Princeton University.

Brooks, W. J. AND K. Donovan (Forthcoming): "Eliminating Uncertainty in Market Access: The Impact of New Bridges in Rural Nicaragua," Econometrica.

Buera, F. J., J. P. KABOSKI, AND Y. SHIN (2012): “The Macroeconomics of Microfinance," Unpublished Manuscript.

(2019): "The Macroeconomics of Microfinance," Unpublished Working Paper, University of Notre Dame.

Burgess, R., M. Greenstone, N. Ryan, And A. Sudarshan (2020): "The Consequences of Treating Electricity as a Right," Journal of Economic Perspectives, 34, 145-169.

Burlig, F. And L. Preonas (2016): "Out of the Darkness and Into the Light? Development Effects of Rural Electrification," Energy Institute at Haas Working Paper 268.

Carvalho, V. M. (2014): "From Micro to Macro via Production Networks," Journal of Economic Perspectives, 28, 23-48.

CASElli, F. (2005): "Accounting for Cross-Country Income Differences," in Handbook of Economic Growth, ed. by P. Aghion and S. Durlauf., Elsevier, 679-741.

CASEY, G. (2018): "Energy Efficiency and Directed Technical Change: Implications for Climate Change Mitigation," Unpublished Working Paper, Williams College.

Clark, D. AND J. Osawa (2010): "Brief Power Blip Jolts Supply of Gadget Chips," The Wall Street Journal.

Di Giovanni, J., A. A. Levchenko, And I. MÉJEAn (2014): "Firms, Destinations, and Aggregate Fluctuations," Econometrica, 82, 1303-1340.

Dinkelman, T. (2011): "The Effects of Rural Electrification on Employment: New Evidence from South Africa," American Economic Review, 101, 3078-3108.

Dzansi, J., S. L. Puller, B. Street, and B. Yebuah-Dwamena (2018): "The Vicious Circle of Blackouts and Revenue Collection in Developing Countries: Evidence from Ghana," Unpublished Working Paper, Texas A\&M.

Eberhard, A., O. Rosnes, M. Shkaratan, And H. Vennemo (2011): Africa's Power Infrastructure, The World Bank. 
Fisher-VAnden, K., E. T. MANsuR, AND Q. WANG (2015): "Electricity Shortages and Firm Productivity: Evidence from China's Industrial Firms," Journal of Development Economics, 114, 172-188.

Foster, V. And J. Steinbuks (2008): "Paying the Price for Unreliable Power Supplies: InHouse Generation of Electricity by Firms in Africa," Africa Infrastructure Country Diagnostic Working Paper No. 2.

FrIED, S. (2018): "Climate Policy and Innovation: A Quantitative Macroeconomic Analysis," American Economic Journal: Macroeconomics, 10, 90-118.

Fried, S., K. Novan, And W. B. Peterman (2018): "The Distributional Effects of a Carbon Tax on Current and Future Generations," Review of Economic Dynamics, 30, 30-46.

Gertler, P. J., O. Shelef, C. D. Wolfram, And A. Fuchs (2016): "The Demand For EnergyUsing Assets among the World's Rising Middle Class," American Economic Review, 106, 13661401.

Golosov, M., J. HAssler, P. Krusell, And A. Tsyvinski (2014): "Optimal Taxes on Fossil Fuel in General Equilibrium," Econometrica, 82, 41-88.

GRAINGER, C. AND F. ZHANG (2017): "The Impact of Electricity Shortages on Firm Productivity: Evidence from Pakistan," Tech. rep., The World Bank.

Hall, R. E. AND C. I. Jones (1999): "Why Do Some Countries Produce So Much More Output per Worker than Others?" Quarterly Journal of Economics, 114, 83-116.

HARDY, M. AND J. McCASLAND (2019): "Lights Off, Lights On: The Effects of Electricity Shortages on Small Firms," The World Bank Economic Review, lhz028.

Hassler, J., P. KRusell, AND C. Olovsson (2015): “Energy-Saving Technological Change," Unpublished Working Paper, IIES.

Hassler, J., P. Krusell, AND A. A. Smith, JR. (2016): "Environmental Macroeconomics," in Handbook of Macroeconomics, ed. by J. B. Taylor and H. Uhlig, Elsevier, vol. 2.

HÉmous, D. (2016): “The Dynamic Impact of Unilateral Environmental Policies,” Journal of International Economics, 103, 80-95.

JACK, K. AND G. Smith (2015): "Pay As You Go: Prepaid Metering and Electricity Expenditures in South Africa," American Economic Review: Papers and Proceedings, 105, 237-41.

JonES, C. I. (2011): "Intermediate Goods and Weak Links: A Theory of Economic Development," American Economic Journal: Macroeconomics, 3, 1-28.

KASSEM, D. (2020): "Does Electrification Cause Industrial Development? Grid Expansion and Firm Turnover in Indonesia," Unpublished Working Paper, University of Mannheim.

LAGAKos, D. (2016): "Explaining Cross-Country Productivity Differences in Retail Trade," Journal of Political Economy, 124, 579-620. 
Lagakos, D., A. M. Mobarak, And M. E. Waugh (2020): “The Welfare Effects of Encouraging Rural-Urban Migration," NBER Working Paper No. 24193.

LeE, K., E. Miguel, AND C. Wolfram (Forthcoming): "Experimental Evidence on the Demand for and Costs of Rural Electrification," Journal of Political Economy.

LEmoine, D. (2018): “Innovation-Led Transitions in Energy Supply,” NBER Working Paper No. 23420.

Lipscomb, M., A. M. Mobarak, And T. Barham (2013): "Development Effects of Electrification: Evidence from the Topographic Placement of Hydropower Plants in Brazil," American Economic Journal: Applied Economics, 5, 200-231.

LIU, E. (2019): "Industrial Policies in Production Networks," Quarterly Journal of Economics, 134, 1883-1948.

Midrigan, V. AND D. Y. XU (2014): "Finance and Misallocation: Evidence from Plant-Level Data," American Economic Review, 104, 422-458.

ReinikKa, R. AND J. Svensson (2002): “Coping With Poor Public Capital,” Journal of Development Economics, 69, 51-69.

RuD, J. P. (2012): "Electricity Provision and Industrial Development: Evidence from India," Journal of Development Economics, 97, 352-367.

Scott, A., E. DARKo, A. Lemma, And J.-P. Rud (2014): "How Does Electricity Insecurity Affect Businesses in Low and Middle Income Countries?" Tech. rep., Overseas Development Institute.

SMEDA (2017): "National Survey of Micro Small And Medium Enterprises (MSMEs)," Tech. rep., Small and Medium Enterprises Development Agency of Nigeria.

Trimble, C., M. Kojima, I. P. Arroyo, And F. MohammadzadeH (2016): "Financial Viability of Electricity Sectors in Sub-Saharan Africa," World Bank Policy Research Working Paper Number 7788.

VIDART, D. (2020): "Human Capital, Female Employment, and Electricity: Evidence from the Early 20th Century United States," Unpublished Working Paper, UCSD.

WORLD BANK (2007): “Technical and Economic Assessment of Off-Grid, Mini-Grid, and Grid Electrification Technologies,” Tech. rep., World Bank, eSMAP Technical Paper 121/07.

World BANK GRoup (2017): “Enterprise Surveys: Technical Report," Https://www.enterprisesurveys.org/. 


\section{Appendix: For Online Publication Only}

\section{A. Solution to the Analytic Version of the Model}

Proof of Proposition 1: For firms with and without generator access, the result that capital demand is increasing in the probability of grid power follows directly from the first order condition for capital. We focus instead on understanding the cutoff, $v^{\star}\left(R_{t}\right)$, below which firms with generator access purchase enough generator capital to operate at full capacity during an outage.

The firm always idles generator capital when the power is on because the price of grid electricity is zero, and this is lower than the marginal cost of fuel to operate the generator (which equals unity). Whether the firm idles productive capital when the power is off depends critically on whether the constraint that $k_{t}^{S} \leq k_{t}^{M}$ binds. We show that this constraint binds for all values of $v$ less than the cutoff, $v^{*}\left(R_{t}\right)$, which we will characterize below.

The modern firm's first order conditions for $k_{t}^{S}$, and $k_{t}^{M}$ from (8) are:

$$
\begin{aligned}
k_{t}^{S}: & \eta\left(1-v_{t}\right) A^{M} z^{1-\eta}\left(k_{t}^{S}\right)^{\eta-1}=R_{t}+1-v+\theta \\
k_{t}^{M}: & \eta v A^{M} z^{1-\eta}\left(k_{t}^{M}\right)^{\eta-1}+\theta=R_{t},
\end{aligned}
$$

and the complementary slackness condition requires that:

$$
\theta\left(k_{t}^{M}-k_{t}^{S}\right)=0
$$

When the constraint does not bind, the solutions are:

$$
k_{t}^{M}=z\left(\frac{v \eta A^{M}}{R_{t}}\right)^{\frac{1}{1-\eta}} \quad \text { and } \quad k_{t}^{S}=z\left[\frac{(1-v) \eta A^{M}}{R_{t}+1-v}\right]^{\frac{1}{1-\eta}}
$$

The constraint does not bind as long as $k_{t}^{M}>k_{t}^{S}$. Substituting in the expressions for $k_{t}^{S}$ and $k_{t}^{M}$ from equation (30) implies that the constraint will not bind as long as,

$$
\frac{v}{R_{t}}-\frac{1-v}{R_{t}+1-v}>0
$$

The left-hand side of equation (31) is increasing in $v$. Define $v^{*}\left(R_{t}\right)$ to be the value of $v$ that makes (31) hold with equality given $R_{t}$. When $v<v^{*}\left(R_{t}\right)$, the constraint binds and the firm rents enough generator capital to operate at full capacity when the power is off. As a result, there are zero idle resources during instants without power. When $v \geq v^{*}\left(R_{t}\right)$, the constraint 
does not bind and the firm rents less generator capital that what is required to operate her productive capital. In this case, she must idle some productive capital when the power is off. Power outages are entirely responsible for the existence of idle resources. When there are no power outages, $v=1$, and equation (30) implies that generator capital equals zero. Zero generator capital combined with zero instants without power results in zero idle resources.

Modern sector entry: We show that the difference in expected profits, $E\left(\pi^{M}(z)\right)-\pi^{T}(z)$ is increasing in $z$. The difference in expected profits for a given entrepreneur with productivity $z$ equals:

$$
E\left(\pi^{M}(z)\right)-\pi^{T}(z)=\gamma \pi^{M}(1, z)+(1-\gamma) \pi^{M}(0, z)-\pi^{T}(z)
$$

Substituting in the relationship that profits equal fraction $1-\eta$ of output yields:

$$
E\left(\pi^{M}(z)\right)-\pi^{T}(z)=(1-\eta)\left[\gamma y_{t}^{M}(1, z)+(1-\gamma) y_{t}^{M}(0, z)-y_{t}^{T}(z)\right]
$$

where,

$$
\begin{gathered}
y^{T}(z)=z\left(\frac{\eta}{R}\right)^{\frac{\eta}{1-\eta}}, \quad y^{M}(0, z)=z v A^{M}\left(\frac{v A^{M} \eta}{R}\right)^{\frac{\eta}{1-\eta}} \text { and } \\
y^{M}(1, z)= \begin{cases}z A^{M}\left(\frac{A^{M} \eta}{2 R+1-v}\right)^{\frac{\eta}{1-\eta}} & : v \leq v^{\star}(R) \\
z\left[v A^{M}\left(\frac{v A^{M} \eta}{R}\right)^{\frac{\eta}{1-\eta}}+(1-v)\left(\frac{(1-v) \eta A^{M}}{R+1-v_{a}}\right)^{\frac{\eta}{1-\eta}}\right] & : v>v^{\star}(R) .\end{cases}
\end{gathered}
$$

Substituting equations (33) - (34) into equation (32) shows that $E\left(\pi^{M}(z)\right)-\pi^{T}(z)$ is increasing in $z$, since, by assumption, $A^{M}>\left[(1-\gamma) v^{1 /(1-\eta)}\right]^{-1 /(1-\eta)}$. 


\section{B. Quantitative Version of the Model}

\section{B.1. Definition of an Equilibrium}

We define a sequence-of-markets equilibrium for this economy as sequences of prices $\left\{W_{t}, R_{t}\right\}_{t=0}^{\infty}$, grid-power probabilities, $\left\{v_{t}\right\}_{t=0}^{\infty}$, productivity cutoffs $\left\{z_{t}^{\star}\right\}_{t=0}^{\infty}$, allocations for the households $\left\{C_{t}, K_{t+1}\right\}_{t=0}^{\infty}$ and allocations for firms of type $(x, z)$ :

$\left\{n_{t}^{T}(x, z), n_{t}^{M}(x, z), k_{t}^{T}(x, z), k_{t}^{S}(x, z), k_{t}^{M}(x, z), e_{1 t}^{G}(x, z), f_{0 t}(x, z)\right\}_{t=0}^{\infty}$ for all $x \in\{0,1\}$ and for all $z \in[1, \infty]$ such that:

1. Given prices, allocations of entrepreneurs across the traditional and modern sectors are consistent with the modern-sector productivity cutoffs, $\left\{z_{t}^{\star}\right\}_{t=0}^{\infty}$, defined in equation (9).

2. Given prices, traditional-sector allocations solve the profit maximization problem for all entrepreneurs in the traditional sector and modern-sector allocations solve the profit maximization problem for all entrepreneurs in the modern sector.

3. Given prices and entrepreneurial profits, household allocations maximize (1) subject to the budget constraints:

$$
\begin{aligned}
C_{t}+K_{t+1}= & Q_{t}+W_{t}+R_{t} K_{t}+(1-\delta) K_{t}+ \\
& \int_{1}^{z_{t}^{\star}} \pi_{t}^{T}(z) d G(z) \int_{z_{t}^{\star}}^{\infty}\left(\gamma \pi_{t}^{M}(1, z)+(1-\gamma) \pi_{t}^{M}(0, z)-\Omega\right) d G(z)
\end{aligned}
$$

and the non-negativity constraints, $C_{t} \geq 0$, and $K_{t} \geq 0$. Variable $\pi_{t}^{T}(z)$ denotes the profits of traditional firms with productivity $z$ and variable $\pi_{t}^{M}(x, z)$ denotes the profits of modern firms with generator access $x$ and productivity $z$.

4. The markets for capital and labor clear:

$$
\begin{aligned}
& K_{t}=\int_{1}^{z_{t}^{\star}} k_{t}^{T}(z) d G(z)+\int_{z_{t}^{\star}}^{\infty}\left(\gamma k_{t}^{M}(1, z)+(1-\gamma) k_{t}^{M}(0, z)+\gamma k_{t}^{S}(1, z)\right) d G(z)+K^{G} \\
& N_{t}=\int_{1}^{z_{t}^{\star}} n_{t}^{T}(z) d G(z)+\int_{z_{t}^{\star}}^{\infty}\left(\gamma n_{t}^{M}(1, z)+(1-\gamma) n_{t}^{M}(0, z)\right) d G(z) .
\end{aligned}
$$

5. The probability of grid power is such that the rationed grid-electricity demand equals the supply (equation (23)). 


\section{B.2. Calibration}

We calculate the average and variable costs of self-generation in each country. All cross-country variation in these cost estimates comes from variation in diesel fuel prices; we assume that the capital and maintenance costs of self-generation are the same for all countries. We use estimates from the World Bank Technical Assessment (World Bank, 2007) to calculate the capital cost of a typical generator. The Technical Assessment reports that a $100 \mathrm{~kW}$ diesel generator would cost 760 dollars per $\mathrm{kW}$, and last 20 years with a capacity factor of 0.8 , (World Bank, 2007). Using an interest rate of 10 percent implies that the annual capital-cost per kWh equals 1.3 cents. The maintenance cost is 5.9 cents per kWh (World Bank, 2007).

We calculate the variable cost of self-generated electricity for the 100 kilowatt diesel generator with 30 percent efficiency. We use the 2014 price of diesel fuel in each country from the World Development Indicators. To convert dollars per liter of diesel fuel into dollars per kWh, we convert liters of diesel fuel into BTUs, and then convert BTUs into kWhs, adjusting for the 30 percent efficiency of the generator.

The average cost per kWh equals the sum of the capital, maintenance and variable costs per $\mathrm{kWh}$. We use a capacity factor of 0.8 when we construct the average cost ratio in the model to ensure that it is consistent with the data. Table B.1 reports the average price per liter of diesel fuel and the variable and average costs of self-generated electricity in each country.

Table B.1: Self-Generation Costs

\begin{tabular}{lccc}
\hline \hline Country & $\begin{array}{c}\text { Diesel Price } \\
(\$ / 1 t r)\end{array}$ & $\begin{array}{c}\text { Variable cost } \\
(\$ / \mathrm{kWh})\end{array}$ & $\begin{array}{c}\text { Average cost } \\
(\$ / \mathrm{kWh})\end{array}$ \\
\hline Ethiopia & 0.89 & 0.28 & 0.35 \\
Ghana & 1.03 & 0.32 & 0.40 \\
Nigeria & 0.84 & 0.26 & 0.34 \\
Tanzania & 1.20 & 0.38 & 0.45 \\
Uganda & 1.11 & 0.35 & 0.42 \\
\hline
\end{tabular}

Note: This first column of this table reports the the price of diesel fuel in 2014 from the World Development Indicators. The second and third columns report the authors' calculations of the variable and average cost of self-generated electricity. All values are in year 2014 dollars.

To calibrate TFP in each country, we compare output per worker in the specific country to output-per worker in Nigeria. Data on output per worker is from the Penn World Tables. We use output per worker in each country in the same year as the World Bank Enterprise Survey for that country, reported in Table B.2. Since the data in Penn World Tables end in 2014 and the 
year of the Enterprise survey in Ethiopia is 2015, we extrapolate, using the 2013-2014 growth rate, to find the value of Ethiopian GDP per capita in 2015.

Table B.2: Year of the World Enterprise Survey

\begin{tabular}{lc}
\hline \hline Country & Enterprise Survey Year \\
\hline Ethiopia & 2015 \\
Ghana & 2013 \\
Nigeria & 2014 \\
Tanzania & 2013 \\
Uganda & 2013 \\
\hline
\end{tabular}

Note: This table reports the year of the enterprise survey in each country.

The baseline calibration uses measures of size of the modern sector from the 2017 Nigerian National Survey of Micro, Small, and Medium Enterprises (SMEDA, 2017). The survey includes a representative sample of micro enterprises (those with less than 10 employees) and small (between 10 and 49 employees) and medium enterprises (between 50 and 199 employees). There is no information on large enterprises (those with greater than 199 employees). The survey has two modules: (1) the micro enterprises are covered in the National Integrated Survey of Households and (2) the small and medium enterprises are covered in National Integrated Survey of Establishments. The survey covers all major sectors of the Nigerian economy, all geographic areas, and includes both formal and informal firms. We do not have access to the raw data from the survey. We take all information from the report, (SMEDA, 2017), assembled by the Small and Medium Enterprises Development Agency of Nigeria. The report compiles two sets of aggregate statistics, one set for micro enterprises and the second set for small and medium enterprises.

We use the survey results to compute the fraction of firms and workers that use electricity. The survey reports the average number of hours an enterprise operates with an alternative source of power. Firms that report zero use of alternative power "have little-to-nil need for [any] power supply" (SMEDA (2017), page 33). Since these firms do not use electricity in the production process, they correspond to the traditional sector in our model. Using this definition, approximately 70 percent of micro enterprises are traditional and 6 percent of small and medium enterprises are traditional. To calculate the fraction of traditional enterprises relative to total enterprises, we divide the number of traditional enterprises by the total number of micro, small, and medium enterprises. ${ }^{9}$

\footnotetext{
${ }^{9}$ We assume that the number of large enterprises equals zero. Micro enterprises are so prevalent that any
} 
We calculate the fraction of total workers that are traditional. Approximately, 76.5 percent of the workers in Nigeria are employed by micro, small, and medium enterprises (SMEDA, 2017). We assume that the remaining 23.5 percent of workers are employed by large firms in the modern sector. To divide the workers at micro, small and medium enterprises into the traditional and modern sectors, we need information on how firm-size varies between the modern and the traditional firms. While this information is not available in the Nigerian survey, we use the fact that 70.4 percent of micro enterprises and 6 percent of small and medium enterprises are traditional, and we assume that each traditional micro enterprise employs one person and each traditional small and medium enterprise employs 10 people.

We use the US GDP deflator to convert all monetary values to 2014 dollars.

reasonable assumption about the number of large enterprises does not have meaningful effects on the fraction of traditional enterprises. In particular, micro, small and medium enterprises account for 76.5 percent of total employment in the Nigerian economy, implying that large enterprises employ at most 183,232,27 people. Since each large enterprise must employ 200 or more people, there can be at most 183,232,27/200 = 91,616 large enterprises. If we assume that there are 91,616 large enterprises, instead of zero, and all large enterprises are modern, then the fraction of traditional enterprises decreases from 0.703 to 0.701 . 


\section{B.3. Results}

Table B.3: Equilibrium Values of Macro-Aggregates in the Initial Steady State

\begin{tabular}{lccccc}
\hline & Ethiopia & Ghana & Nigeria & Tanzania & Uganda \\
\hline Grid-electricity price: $P^{G}$ & 0.03 & 0.10 & 0.08 & 0.07 & 0.08 \\
Grid-electricity capital: $K^{G}$ & 0.003 & 0.271 & 0.156 & 0.094 & 0.162 \\
Grid-electricity supply: $E^{G}$ & 0.02 & 0.40 & 0.27 & 0.19 & 0.28 \\
Fraction of modern labor: $N^{M}$ & 0.05 & 0.55 & 0.63 & 0.33 & 0.47 \\
Fraction of modern entrepreneurs: $Q^{M}$ & 0.01 & 0.21 & 0.30 & 0.09 & 0.15 \\
Probability of grid power: $v$ & 0.51 & 0.78 & 0.41 & 0.75 & 0.82 \\
\hline
\end{tabular}

Note: This table reports the equilibrium values of a number of variables in the initial steady state in each country. While the units of the grid-electricity price, capital, and supply are not meaningful independent of the model, the comparison of the different values across countries is meaningful. In particular, note that grid electricity price, capital, and supply are extremely low in Ethiopia in the initial steady state.

\section{Figure B.1: Long-Run General-Equilibrium Effect of Eliminating Outages When All Modern} Firms Have Generator Access

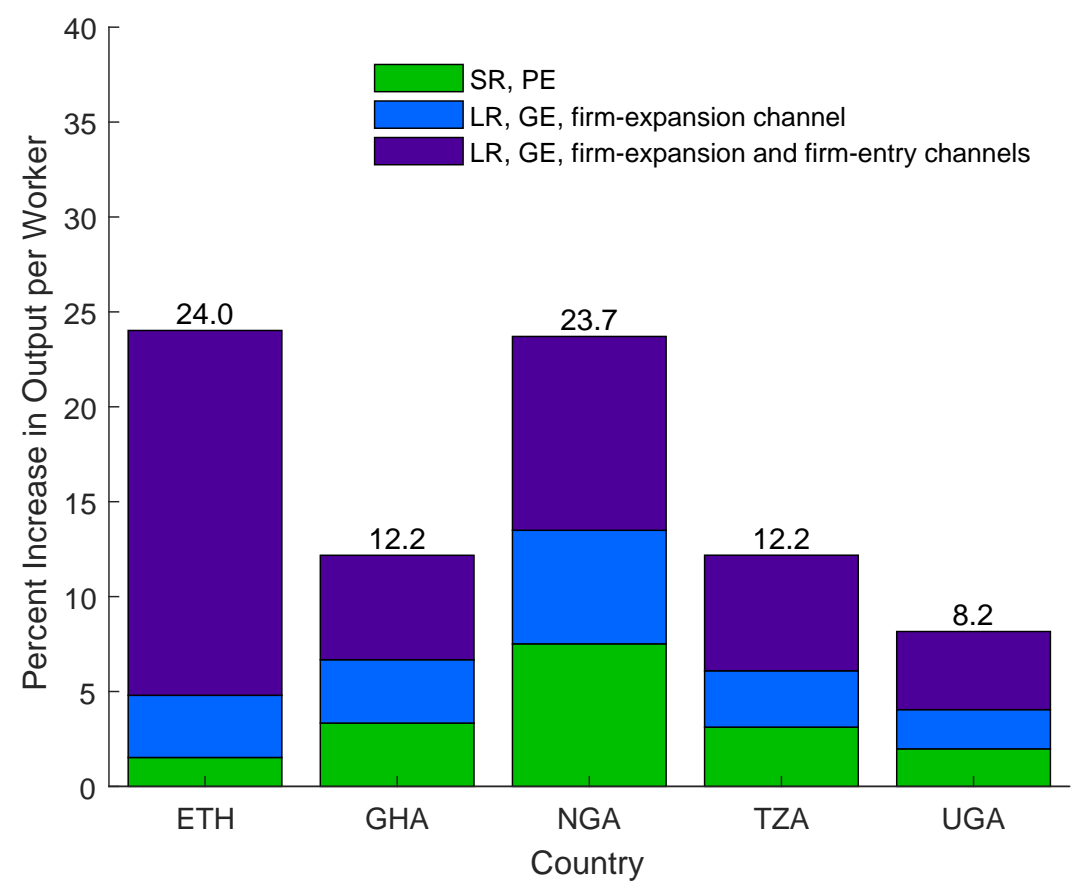

Note: The height of each bar equals the total steady-state increase in output per worker from eliminating power outages in each country in the counterfactual world in which all modern firms have access to generators in the initial steady state. The green, blue and purple regions of each bar correspond to the relative contributions from the short-run partial-equilibrium effect, the firm-expansion channel and the firm-entry channel, respectively. 


\section{Additional Survey Results}

Figure C.1: Frequency of Power Outages of Surveyed Firms

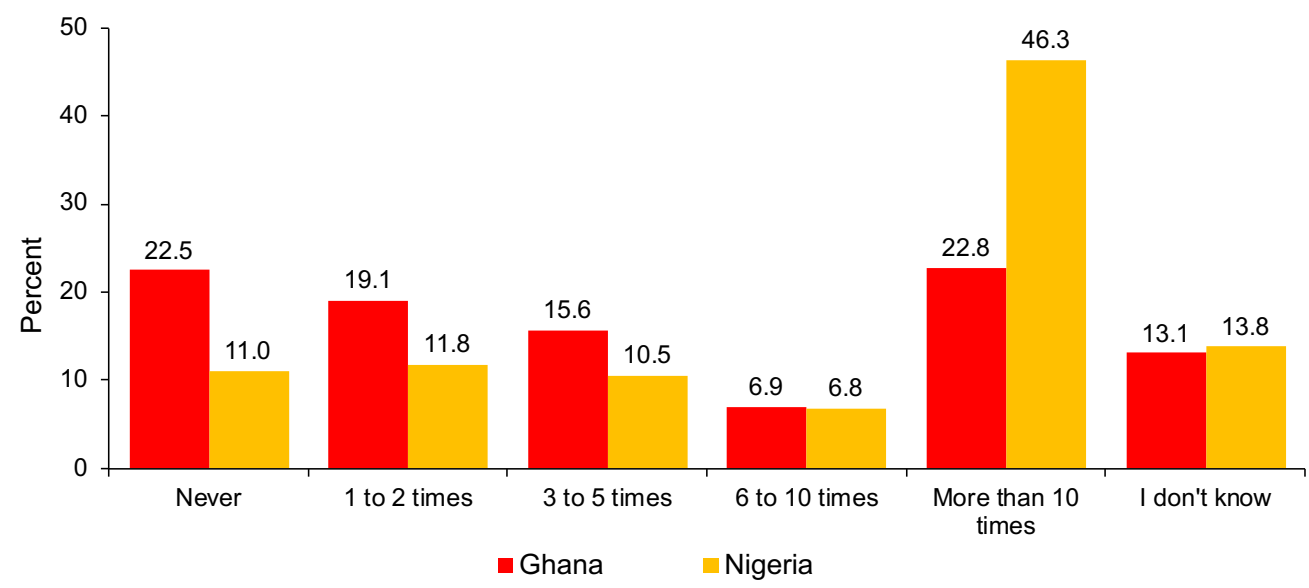

Note: This figure reports the frequency of power outages in the previous year among the surveyed firms in Ghana (red) and Nigeria (yellow).

Figure C.2: Average Monthly Revenues of Surveyed Firms

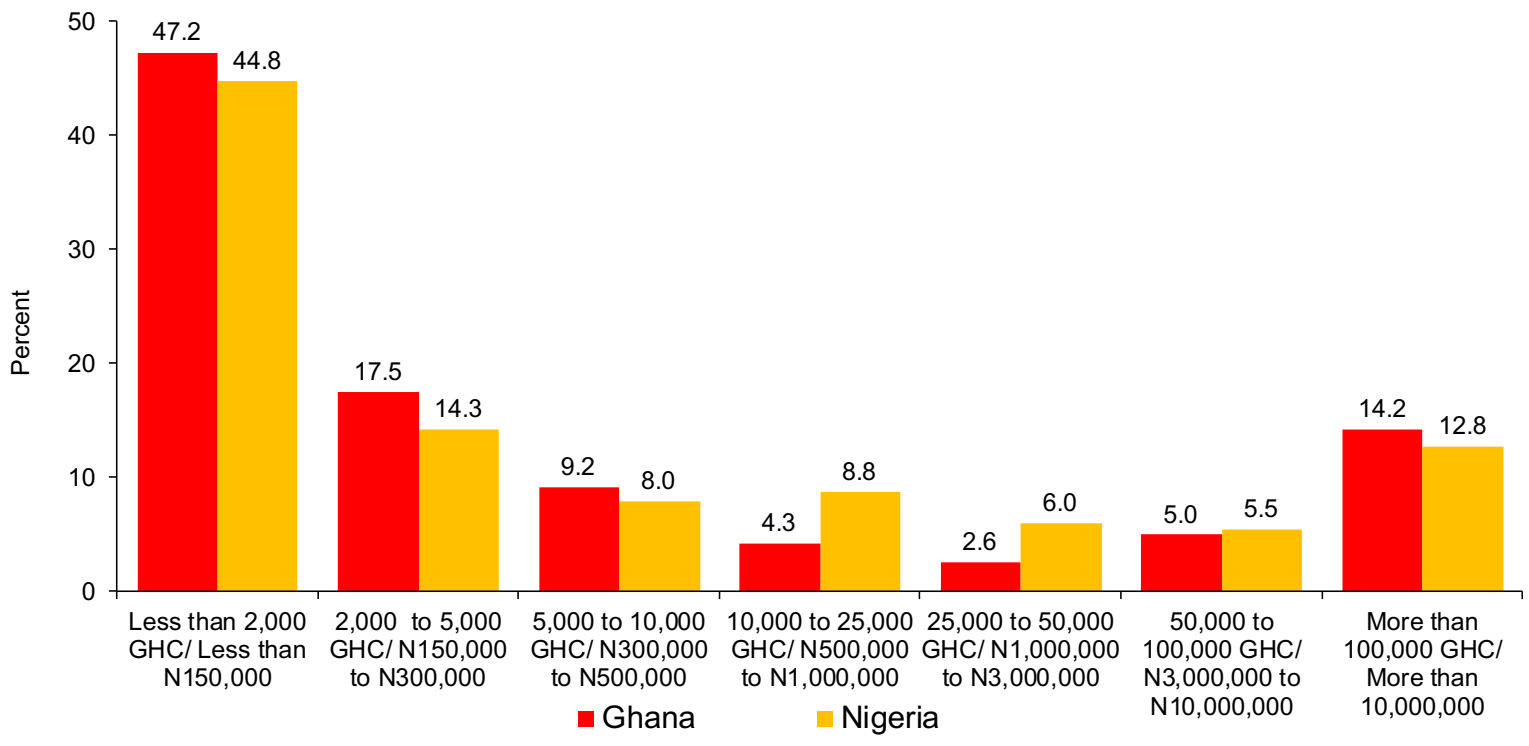

Note: This figure reports the average monthly revenues among the surveyed firms in Ghana (red) and Nigeria (yellow). 